ARCHIVO ESPAÑOL DE ARTE, LXXXVI, 343

JULIO-SEPTIEMBRE 2013, pp. 201-220

ISSN: 0004-0428

\title{
CORNELIS SCHUT: NUEVAS PINTURAS IDENTIFICADAS EN BÉLGICA Y ESPAÑA
}

\author{
JAHEL SANZSALAZAR
}

\begin{abstract}
Las siete nuevas pinturas que se restituyen aquí a Cornelis Schut suponen importantes aportaciones al catálogo razonado del pintor, publicado en 1996. Tras una explicación sobre la significación del pintor y su relación con Rubens, el autor hace un recorrido por las obras de su mano que hubo y hay en España; entre ellas, una Santa Ana Trinitaria, firmada e inédita, que corresponde mejor al grabado de Eynhoudts que la réplica conocida en Namur con la que se asocia hasta hoy. Se le atribuyen también varias obras del Patrimonio belga que constaban con erróneas atribuciones: dos réplicas en la colegiata de Santa Gertrudis de Nivelles, un lienzo en Pipaix, una Santa Gertrudis en su lecho de muerte de interesante iconografía, en la iglesia de Malinas, y dos composiciones con la Asunción de la Virgen, una correspondiendo al dibujo conocido en Varsovia y otra al grabado de Eynhoudts.

Palabras clave: Pintura flamenca; siglo XVII; Escuela de Rubens; Amberes; Cossiers; Thulden; Colegio Imperial de Madrid; Santa Cruz de Retamar; Conde de Floridablanca; Jesuitas; Hospital de San Julián de Málaga; Overijse; Jezus-Eik; Aspelare.
\end{abstract}

\section{CORNELIUS SCHUT: NEWLY IDENTIFIED PAINTINGS IN BELGIUM AND SPAIN}

The seven newly identified paintings restituted here to Cornelis Schut are important additions to his $\mathrm{Ca}$ talogue Raisonné, published in 1996. Following a discussion of the artist's significance and relation to Rubens, the author traces his oeuvre in Spain in the past and present. Among these works, a signed and heretofore unknown Virgin and Child with St Anne that better relates to the print by Eynhoudts than the known replica in Namur. Other works with incorrect attributions in Belgian collections are restituted to the artist as well: two replicas in St. Gertrude's College in Nivelles, a canvas in Pipaix, a St. Gertrude on her death bed, displaying an interesting iconography, in the church of Malinas, and two compositions of the Assumption of the Virgin, one corresponding to the known preparatory drawing in Warsaw, and the other to an engraving by Eynhoudts.

Key words: Flemish painting; 17th century; Rubens School; Antwerp: Cossiers; Thulden; Imperial College of Madrid; Santa Cruz de Retamar; Count Floridablanca; Jesuits; Hospital of Saint Julian, Malaga; Overijse; Jezus-Eik; Aspelare.

En Bélgica o en España, la producción religiosa de Cornelis Schut (Amberes, 1597-1655) está ligada al destino devoto de la Contrarreforma impulsada desde aquí. Pretendemos en estas páginas dar a conocer algunas nuevas obras de Cornelis Schut, a añadir a la monografía de la Dra. Getrude Wilmers, publicada en $1996^{1}$. Pero, antes de adentrarnos en las pinturas y en las evidencias esti-

\footnotetext{
1 WiLmers, 1996.
} 
lísticas para su atribución a Cornelis Schut, creemos oportuno introducir algunas precisiones respecto a sus vínculos con Rubens y con España.

A Cornelis Schut se le vino a llamar "satélite", como parte del grupo, no del todo definido, de discípulos y colaboradores de Rubens, pintores que, de una forma u otra, gravitaron a su alrededor y siguieron su estilo ${ }^{2}$. Así, su fortuna crítica se construyó, como la de tantos otros, a la sombra de la del maestro. No obstante su personalidad artística es tan singular como su significación en el desarrollo de la pintura barroca en la escuela de Amberes.

Pese al olvido que le propinó el siglo XIX con su aversión al barroco, el arte de Cornelis Schut fue bien recibido por sus contemporáneos, siendo merecedor de no pocos elogios por parte de poetas, tratadistas y viajeros, que subrayan su genio creativo, el carácter prolífico de su obra y la buena reputación ganada en el extranjero ${ }^{3}$. Pero su arte no sería nunca tan entendido como en su tiempo. Ya a mediados del siglo XVIII, Jean Baptista Descamps calificaba sus composiciones de "duras, secas y sin efectos", o "mediocres y confusas", valorando sólo aquéllas de "correcto diseño, genio y belleza clásica" que asociaba a Van Dyck ${ }^{4}$.

Pero, salvo en raras excepciones, el estilo de Cornelis Schut tiene poco que ver con la belleza ideal y elegante de Van Dyck. Precisamente, se distingue por su originalidad entre los seguidores de Rubens. Las composiciones rebuscadas, los escorzos y la agitación en las posturas de los personajes, el colorido opaco y contrastado, el uso de contornos acusados y sombras oscuras, y la intensidad de la luz que caracterizan su estilo, se han visto hasta fechas recientes como signos de mediocridad $^{5}$.

No obstante, la sensibilidad de Cornelis Schut es distinta, pues su estilo se forjó en mayor medida con el viaje a Italia (1624-1627) ${ }^{6}$ que con su contacto con Rubens. Toma del barroco romano el dramatismo compositivo, cromático y expresivo. De vuelta a Amberes, su colaboración con Rubens se limitó a las decoraciones para la entrada triunfal del cardenal-infante en la ciudad en $1635^{7}$. También colaboró, junto a Gaspar de Crayer, en las de Gante ${ }^{8}$. Pero Schut trabajó de manera independiente en grandes retablos para las iglesias de Flandes, produjo pinturas de contenido religioso y profano para patronos privados, decoró numerosas guirnaldas de flores y frutas, destacó especialmente por su abundante obra grabada, diseñó cartones para tapices e incluso platerías".

Jacques Foucart vio en él a un "rococó avant la lettre"10, y así lo confirma la monografía de Gertrude Wilmers, que devolvió al pintor su importante papel transmisor del alto barroco romano en los Países-Bajos del sur, reuniendo su obra y de gran utilidad para las nuevas identificaciones que proponemos.

Es lástima que quede tan poca obra suya en España ${ }^{11}$. Aquí conocemos mejor a su sobrino y homónimo, Cornelis Schut el Joven (Amberes 1629-Sevilla 1685), que siguió el estilo de Murillo,

2 HAIRS, 1977: 199-216.

3 De Bie, 1661: 103. Papebrochius, 1700, IV: 407; V: 220, 341, 348. Caljé van den Berg, 1973: 298.

${ }^{4}$ DESCAPMS, 1769: 48, 137, 151, 155, 161, 194, 195, 245, 246.

5 HAIRS, 1977: 208.

${ }^{6}$ Vlieghe, 1971; 1990.

${ }^{7}$ Nada queda de la participación de Schut en este programa decorativo en el que se solicitó a los mejores pintores de Amberes. Sabemos que se le encargó pintar la estructura del Arco de bienvenida, del que sólo subsiste hoy el boceto de Rubens. Véase al respecto MARTIN 1972: 21-22. WiLMERS, 1996: 81-82.

${ }^{8}$ VAn de Velde \& Vlieghe, 1967. Vlieghe, 1969-1972: 183-190.

9 Rubens poseyó una bandeja de plata decorada con figuras alegóricas diseñadas por Schut y ejecutadas por Theodoor de Rasier (GÉnARD, 1882: 226-228, 243. WiLMERS, 1996: 14, 46).

${ }^{10}$ Foucart, in Lille/Calais/Arras, 1977 : 13. In Paris, $1977:$ 208-209.

11 Díaz PADRón, 2004: 80-84. El profesor Díaz Padrón nos comunicó el hallazgo, en colección privada española, de un lienzo con Susana y los Viejos (lienzo, 105 x $125 \mathrm{~cm}$ ), cuyo estudio detenido prepara, junto con otras obras inéditas y localizadas en España (DíAZ PADRóN, en preparación). 
siendo miembro fundador de la Academia de esta ciudad en $1660^{12}$. Era hijo de su hermano Pieter, miniaturista e ingeniero, al servicio del rey de España desde 1639 y afincado en Sevilla después de 1644.

En otro tiempo, la iglesia de San Francisco Javier del Colegio Imperial de Madrid (hoy iglesia de San Isidro) poseía uno de los retablos más monumentales de Cornelis Schut, el Viejo, con San Francisco Javier bautizando a los indios, pintura de 1648 que ven allí Palomino y Ponz, precisando este último el nombre del pintor ${ }^{13}$. En 1926 el padre Gálvez identificó la obra en la parroquia toledana de Santa Cruz de Retamar, publicando la documentación detallada del encargo ${ }^{14}$. De la pintura hoy sólo se conserva una antigua fotografía, pues se destruyó durante la Guerra Civil. No se ha precisado hasta ahora cómo y cuándo salió de Madrid para llegar a Retamar. Hoy descubrimos que fue regalo del ministro Floridablanca durante su ministerio (1789-1792), noticia hasta ahora inadvertida que leemos del historiador José Cornide, que vio el retablo en la parroquia toledana en $1798^{15}$. El modeletto ha sido descubierto en fechas recientes en los Jesuitas de Brujas ${ }^{16}$. No extraña que Schut haya preparado cuidadosamente tan ambiciosa composición. Es clara la inspiración en el lienzo del mismo asunto que pintó Rubens hacía 1617, hoy en el Kunsthistorisches Museum de Viena ${ }^{17}$. La colección de Caja Madrid (actualmente Bankia) posee una copia ${ }^{18}$ que hubiera sido interesante investigar, pero la entidad bancaria no ha facilitado su estudio pese a nuestras repetidas gestiones.

Por abandono se perdió gran parte de unos Desposorios de la Virgen de su mano, retablo de gran tamaño rematado en medio punto que ornaba la iglesia del Hospital de San Julián de Málaga ${ }^{19}$. Hoy sólo se conservan unos fragmentos, objeto de una restauración poca afortunada ${ }^{20}$.

Al margen de las guirnaldas (de las que trataremos en otro artículo por venir) ${ }^{21}$, a España llegaron tapices según sus diseños, probablemente una serie con las Siete Artes liberales que recibió

12 Véase sobre el pintor, KinKead, 1982: 37-44. Díaz Padrón 1987: 205-210. De la Sierra \& Lorenzo y Quiles, 1998: 83-105.

13 "El quadro grande con multitud de figuras, en donde está San Francisco Xavier sobre un pedestal bautizando indios, puesto en la pared de un rellano de la escalera principal, es de Cornelio Scut, pintor de Anvers" (Ponz, 1772-1794, V: 97; $3^{\mathrm{a}}$ ed. 1793, V: 94).

${ }^{14}$ Gálvez, 1926: 670-674, 736-737. SÁnchez Cantón, 1952: 51-52. Díaz Padrón, 1976, vol. III: 1012-1013. Wilmers, 1996: 151, cat. A86 (véase Lit.). También citado en Capmany y Montpalau, 1862: 284. Alamán 1855: vol. VII: 17 (Schut).

${ }^{15}$ En su viaje de Madrid a Villaviciosa, el 21 de octubre está en Retamar: "Esta iglesia está adornada de varias pinturas y en el altar mayor tiene una bastante grande, en que San Francisco Javier está predicando en la India. Esta pintura (que) fue hecha para un sitio de más elevación en que sin duda estuvo el Colegio Imperial de Madrid, de donde fue traída con las del cuerpo de la iglesia en el Ministerio del Señor Conde de Floridablanca, regalada por dicho excelentísimo por recomendación de D. Laureano, contador a la sazón de temporalidades, y de D. N. Bermúdez, su mayordomo, ambos naturales del pueblo" (ABASCAL y CeBrián, 2009: 318).

${ }^{16}$ Lienzo, 104 x $82 \mathrm{~cm}$. Wilmers se interroga sobre la existencia de una pintura con el mismo asunto en Brujas, por la anotación "Pictura est in templo nostro Brugis" en un dibujo de idéntica composición (París, École des Beaux-Arts), pero no tiene constancia de su localización en la iglesia (Wilmers, 1996: 153). El reciente hallazgo, del que da breve noticia la prensa local (Gazet van Antwerpen, 13-I-2006. De Standaard, 14-I-2006), se debe a Paul Begheyn SJ, a quien agradecemos la gentileza de habernos hecho llegar su artículo (BEgHEYN, 2007). Véase también GutiérRez PASTOR, 2007: 115-116.

${ }^{17}$ A propósito de esta pintura véase VLIEGHE 1972: 29, $\mathrm{n}^{\mathrm{o}} 104^{\mathrm{a}}$.

18 Recogida en Díaz PAdRón, 1976, vol. III: 1012-1013. Wilmers proporciona, por error, que fue SÁnChEz CANTÓN el que dio noticia de ésta, pero nada leemos sobre ella en su publicación (Cf. Sánchez Cantón, 1952: 51-52). Véase también AREÁN, 1989: 27.

${ }^{19}$ Lienzo, 318 x $220 \mathrm{~cm}$ (dimensiones originales), rematado en medio punto. Ponz, 1794: 193 ("lo hizo el Caballero Manrique, aunque algunos lo tienen por de Rubens”). Angulo ÍÑIguez, 1971: 271 (atribuido a Manrique). Díaz Padrón, 1976, vol III: 1013 (Cornelis Schut). Clavijo García 1981: 63, lám IV (Cornelio de Vos).

${ }^{20}$ Instituto de Conservación y restauración de obras de Arte. Catálogo de obras restauradas 1980-1982: 157. SAURET Guerrero, 1999.

${ }^{21}$ SANZSAlAZAR (en preparación).

Arch. esp. arte, LXXXVI, 343, JULIO-SEPTIEMBRE 2013, 201-220, ISSN: 0004-0428 
Don Francisco Garraza y Aguilar, desde Brujas, en 1654-5522. Hay ejemplares en la Catedral de Zamora ${ }^{23}$, en Castrojeriz (Burgos), y en Córdoba.

Leemos en publicación de la Real Academia de la Historia, a propósito de un tapiz con la $\mathrm{Co}$ ronación de Carlos V en Bolonia, la aceptación de la participación de Schut en el diseño de la cenefa $^{24}$. Es una hipótesis abandonada, que expresó Versyp en 1955, posiblemente debida a que el proyecto para la entrada en Gante del cardenal-infante estuvo en manos de Gaspar de Crayer y Cornelis Schut. Pero el lienzo que sirvió a esta escena, hoy en el Ayuntamiento de esta ciudad, es de Gaspar de Crayer ${ }^{25}$ y el tapiz correspondiente, del que se conoce la serie completa en el Palacio Granvelle, en Besançon, se asocia a su diseño ${ }^{26}$. Las composiciones de Schut son otras.

Afortunadamente durante los últimos años algunas obras han venido a enriquecer el coleccionismo privado español. Un bello boceto con la Circuncisión conservaba desde 1976 Roberto Otero $^{27}$, fotógrafo y amigo de Picasso fallecido en Palma de Mallorca en 2004. En fechas recientes ingresa en el coleccionismo madrileño una Virgen rodeada de una gloria de ángeles, obra reconocida de su mano, procedente de una colección británica ${ }^{28}$.

También en colección privada está una Virgen con el Niño y Santa Ana (fig. 1$)^{29}$, pintura firmada y desconocida en la bibliografía del pintor, sobre la que nos detendremos. El lienzo es idéntico al conocido en la iglesia de San Juan Bautista en Namur, de menores proporciones (fig. 2 ) $^{30}$, concebido para ornar el monumento funerario de Marguerite Carlier en $1641^{31}$, en un altar de mármol y alabastro en la nave derecha del coro.

Santa Ana está en la cúspide de la composición en pirámide, con el Niño Jesús sentado en sus rodillas y la Virgen en el lado derecho, arrodillada ante él. El Niño lleva una manzana en la mano izquierda y bendice con la derecha, mientras la Virgen le acaricia con dulzura el piececillo. Santa Ana extiende los brazos para rodear a las dos generaciones de su progenitura, mientras es coronada con flores por dos angelitos que revolotean en la parte superior, junto a un rompimiento de gloria con cabezas de querubines y un paisaje con celajes.

La reunión de las tres generaciones de la Sagrada Familia-Anna selbdritt para los germánicosse considera el equivalente terrestre de la Santísima Trinidad ${ }^{32}$. La manzana en la mano del Niño alude al árbol del conocimiento. El Niño Jesús es visto como el nuevo Adán, y el fruto es símbolo

22 Véase Delmarcel y Duverger, 1987 : 94, 146, 459, 538. Wilmers, 1996: 286, nn. 3.

23 Véase Gómez y Chillón, 1925: 105-110. Asselberghs, 1999.

24 Victoria Ramírez, in Maier, 2005: 42-44, $n^{\circ} 21$. Constatamos errores metodológicos que se prestan a confusión, pues señala en la bibliografía títulos que no corresponden a la pieza en estudio (como DE PoORTER, 1985, que no habla de esta serie sino de la de las Siete Artes Liberales, o Vlieghe, 1972, que trata aquí de la serie de Besançon); olvidando en cambio otros títulos donde sí se menciona la pieza (como la exposición Carlos Quinto y su ambiente, cat. exp. Toledo, 1958: 243, no 650 y Vlieghe, 1969: 100, nn. 44).

25 VLIEGHe, 1972a: 117-118, cat. A47.

26 VLIEGHE, 1972 ${ }^{\mathrm{a}}$. 125, cat. A55.

27 Tabla, 49,5 x $38 \mathrm{~cm}$. Wilmers, 1996: 111, cat. A48.

${ }^{28}$ Lienzo, 66 x $48.3 \mathrm{~cm}$. Procede de Oxon, Inglaterra, de la colección de David Sloss [Vid. Wilmers, 1996: 173, cat. A111 (la registra como en soporte de tabla)). Pasó sucesivamente en subastas de Londres (Sotheby’s, 12/07/2001, lot 348; 16/04/2002, lot 247) y Madrid (Ansorena, 07/10/2002, lot 35) donde se apunta, correctamente, como lienzo.

${ }^{29}$ Lienzo, 159,2 x 120,9 cm. Firmado en el zócalo a la izquierda, a los pies de la Virgen: "C. Schut". Valencia, colección particular.

${ }^{30}$ Lienzo, 112,5 x 92,5 cm. Namur, iglesia de San Juan Bautista (Véase Wilmers, 1996: 115, cat. nº A54).

31 La inscripción de dicho documento nos proporciona la fecha de 1641 y dice así: "A l'honneur de Dieu et de / Madame Ste Anne Diedonnée / Carlier at faict dresser / ceste table dautel 1'an 1641 / pour memoire de Marguerite / Carlier sa cousine en son / temps grande bienfaictresse / de ceste eglise laquelle / mourut fille agee de 72 ans / le 25 janvier l'an 1639 et fut / sepulturee devant" (Cit. WiLmers, 1996 : 115).

32 A propósito del asunto iconográfico véase RÉAU, 1958, II, 2: 143-146. 


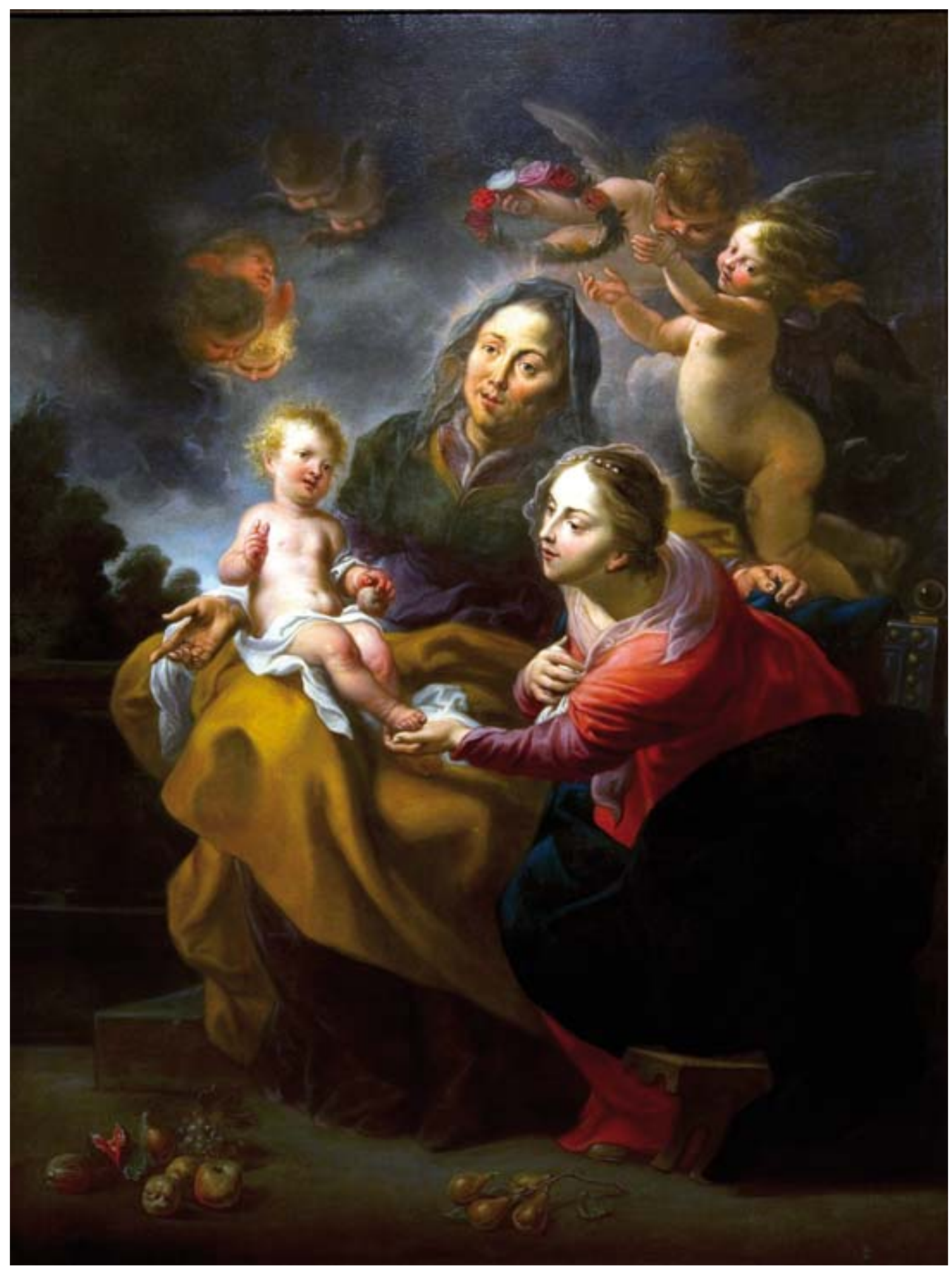

Fig. 1. Cornelis Schut. Santa Ana con la Virgen y el Niño (Santa Ana Trinitaria). Firmado: “C. Schut”. Valencia, colección particular.

Arch. esp. arte, LXXXVI, 343, JULIO-SEPTIEMBRE 2013, 201-220, ISSN: 0004-0428 


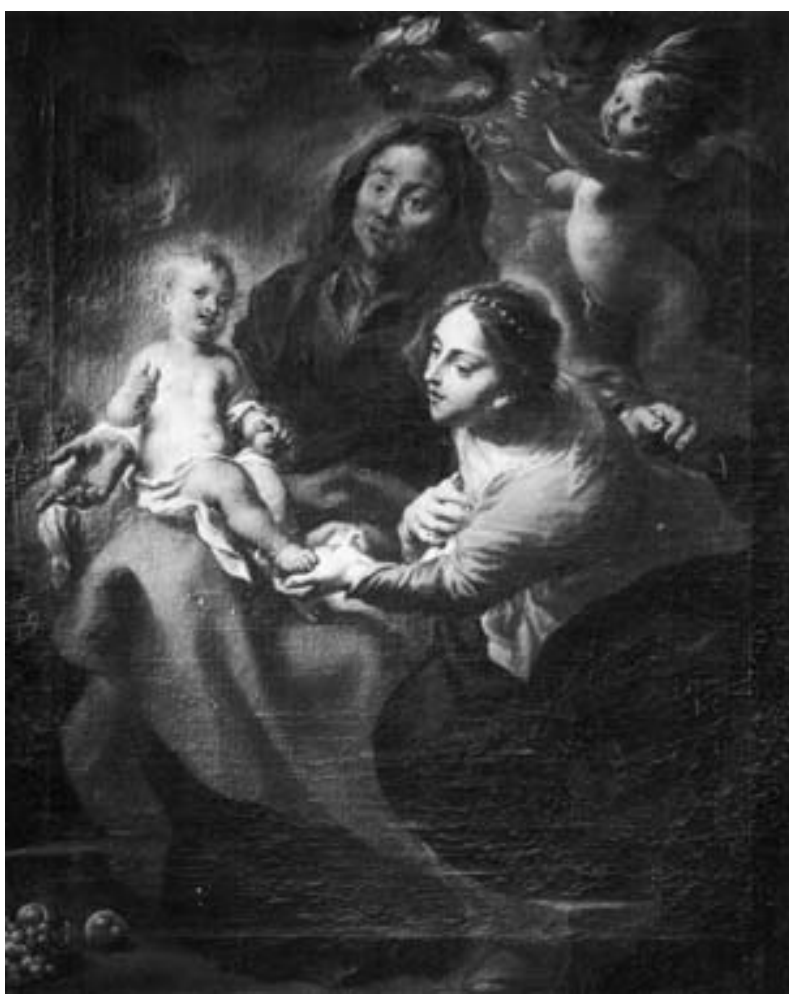

Fig. 2. Cornelis Schut. Santa Ana con la Virgen y el Niño (Santa Ana Trinitaria). Namur, Église de Saint Jean Baptiste.

de la Salvación por su sacrificio para redimir el pecado del hombre ${ }^{33}$. A la misma idea aluden las manzanas en el suelo, así como los higos, con cuyas hojas cubrieron Adán y Eva su desnudez tras el pecado original ${ }^{34}$. El racimo es símbolo de la sangre de Cristo derramada ${ }^{35}$ y las peras se relacionan con el Cristo encarnado y su amor por la humanidad ${ }^{36}$.

Destacamos la calidad de la pintura. En el pasado se tuvo por Rubens, y le añadieron una falsa firma ("P. P. Rubens. 1633") que fue retirada tras la limpieza del lienzo ${ }^{37}$, apareciendo así, en la parte inferior izquierda, la firma de su auténtico autor: "Co. Schut" (fig. 3), grafía ausente en el ejemplar citado de la iglesia belga ${ }^{38}$. Gertrude Wilmers lamenta el estado de conservación de la réplica conocida y advierte la suciedad acumulada, señalando en particular el mal estado del rostro de Santa Ana y la dificultad de apreciar los colores y la pincelada. Estas circunstancias dificultan un juicio ecuánime para dar prioridad a una u otra.

En cualquier caso, interesante es comparar ambas versiones y hacer notar algunas diferencias. En la réplica inédita que estudiamos, Schut concibió la composición con mayor holgura, probablemente al no verse supeditado a las medidas del altar que debía albergar la otra versión. Las figuras se distribuyen en el lienzo sin apreturas, con mayor espacio circundante. Fue también más generoso en las frutas, representadas con mayor prodigalidad. Lo mismo sucede en la parte superior, con mayor espacio en el cielo.

Pero lo más significativo es que el grabado realizado por Remoldus Eynhoudts (fig. 4) ${ }^{39}$, hasta ahora asociado a la réplica de Namur, corresponde con mayor exactitud con la pintura que estudiamos. Esto se distingue particularmente en las frutas a los pies de Santa Ana: el racimo de uvas se ubica

\footnotetext{
33 Vid. Ferguson, 1966: 32.

${ }^{34}$ Gen, 3: 7; Vid. Ferguson, 1966: 37.

35 Ferguson, 1966: 38.

${ }^{36}$ Ferguson, 1966: 46.

${ }^{37}$ La restauración tuvo lugar entre 1990 y 1994. Cf. Londres (Christie's, 06-07-1990, nº 103); Londres (Christie's, 9-12-1994, nº 227).

${ }^{38}$ Pocas son las pinturas conocidas donde consta la firma de Cornelis Schut. Es el caso de la Conversión de San Pablo de la iglesia de la misma advocación en Colonia, que ostenta en la parte inferior izquierda: "Cor Schut (sic) Antverpia"; de la Asunción de la Virgen de la Catedral de Amberes, firmada con letras capitales: "CORNELIS SCHUT FE, 1647"; de Susana y los viejos, y la Alegoría de la Abundancia, así como del retablo perdido del Colegio Imperial de Madrid, que tenía la firma, borrada y repintada, junto a la fecha de 1648 (véase Wilmers, 1996: cats. A67, A78, A29 y A34).

${ }^{39}$ Con la inscripción: "C. Schut pinxit" y el sello de la colección Lugt, 240. Wurzbach II: 15; Hollstein, 15-1(3). Amsterdam, Rijksmuseum, Inv. RP-P-OB-50.510.
} 
delante de dos manzanas en el lienzo de Namur, mientras que en la pintura que estudiamos y en el grabado está detrás. Esto demuestra que el lienzo que estudiamos fue el que sirvió al grabado y no la réplica de Namur como hasta ahora se creía. En la parte inferior corre una inscripción en flamenco antiguo que dice así: Waer af Ick hebbe d'origenael schilderij ende betaelt Inde wijtroep 300 guldens (del cual tengo en mi posesión la pintura original pagada en subasta 300 florines). De esto se deduce que tanto la pintura como el grabado estaban en la misma colección. Ignoramos la

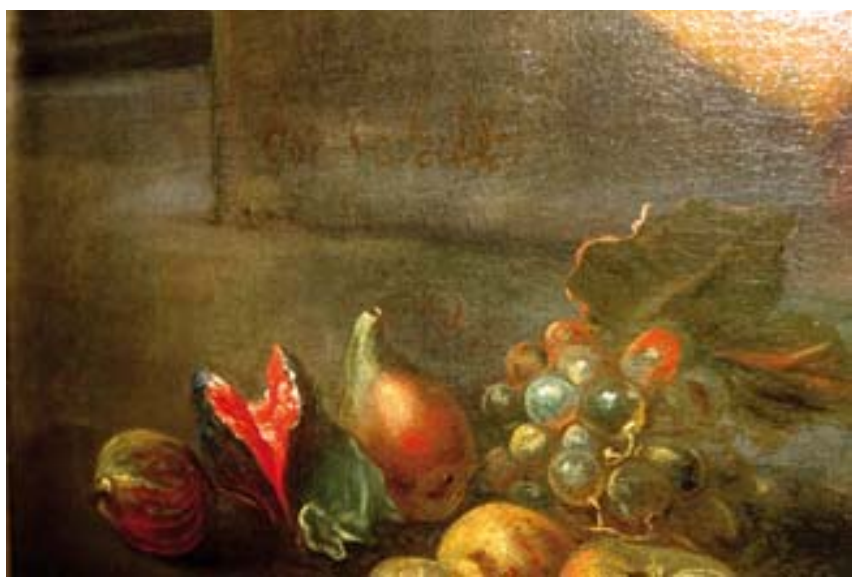

Fig. 3. Detalle de Fig. 1, con la firma "Co. Schut". identidad del coleccionista en cuestión, pero el precio pagado es el habitual en vida del pintor ${ }^{40}$. Cornelis Schut guardó lo que podría ser la plancha de cobre para el grabado: "Una nuestra señora con Jesús y Santa Ana" ${ }^{\text {, }}$, registrada entre numerosos grabados y dibujos en el inventario de sus bienes (1664).

Pinturas con el mismo asunto figuran inventariadas en las colecciones de Amberes del siglo XVII: una en posesión de Elisabeth Waeyens, esposa del escultor Hans van Mildert, según su inventario de 1657: "Una pintura de Nuestras Señoras, Jesús y María Ana de Schut"42 y otra entre los bienes del cuñado del pintor, Willem Huymans, muerto en Amberes en 1685: "una pintura según Schut y por él retocada representando a la Santa Madre Ana, Nuestra Señora, y el Niño Jesús" ${ }^{\prime 3}$. Tanto este inventario de su cuñado, como el de la viuda de Norberto Schut $(1689)^{44}$, distinguen los originales del pintor de las copias retocadas por él, lo que testimonia de una práctica habitual y afín a la de Rubens en su taller.

La composición está articulada en un esquema triangular, superponiendo ritmos circulares con el brazo de la Virgen, el cuerpo del Niño y los angelitos. La Virgen rompe el plano hacia el espectador creando un ritmo tenso, contrastando las luces y sombras con violencia. Cornelius Schut busca la armonía cromática de tintas naranjas, rojas y pardas. En el rostro de Santa Ana se lee la preocupación del trágico devenir del Niño. El modelo del Niño es muy similar en la Sagrada Familia con Santas y ángeles de la iglesia de San Nicolás de Hemiksem ${ }^{45}$. Repite en la Virgen el rostro de Santa Ana, lógicamente más avejentada en nuestro lienzo.

${ }^{40}$ Cf. Wilmers, 1996: 225, doc. n ${ }^{\text {o }} 38 ; 227$, doc. nos. 48, 52; 231, doc. $n^{\text {o }} 92$.

41 "Capittel van platen: (...) ende een Lievevrouwken met een Jesuken ende Sint-Anneken, $\mathrm{N}^{\circ} 10^{\prime}$ [Inventaris van de platen, prenten en tekeningen door Cornelis Schut, kunstschilder, in het huis van N. N de Licht achtergelaten, 3 Juni 1664, Stadsarchief Antwerpen (S. A.), Notaris J. Van Nos 4269 (1664), f 109v-111v; publicado por DuvERGER, 19842004: vol. VIII: 378].

42 "Een schilderije van Ons-Lieve-Vrouwen, Jesus ende María Anna van Schut" [Amberes, SA, Notaris A. van der Donck 3774 (1657), fo 198, publicado en DuVERGER, 1989: 387-414; y de nuevo en DuverGER 1984-2004: VII: 321; Cit. WiLMERS, 1996: 189, nº B144].

43 "Een stuck schilderye naer C. Schut ende an hem geretocqueert representerende de H. Moeder Anna, Onse L. Vrouwe, ende het kindeken Jesus“ (Amberes, Staadsarchiv, Not. Nic. Bernier, 1685-1686, n 202; parcialmente publicado por Denucé 1932: 329-333, nº 107; Duverger, 1984-2004: vol. XI: 343; Cit. Wilmers, 1996: 189, nº B145, doc. B3, nº 17).

44 Véase Duverger, 1984-2004: vol. XI: 586.

45 Wilmers, 1996: cat. A89. 


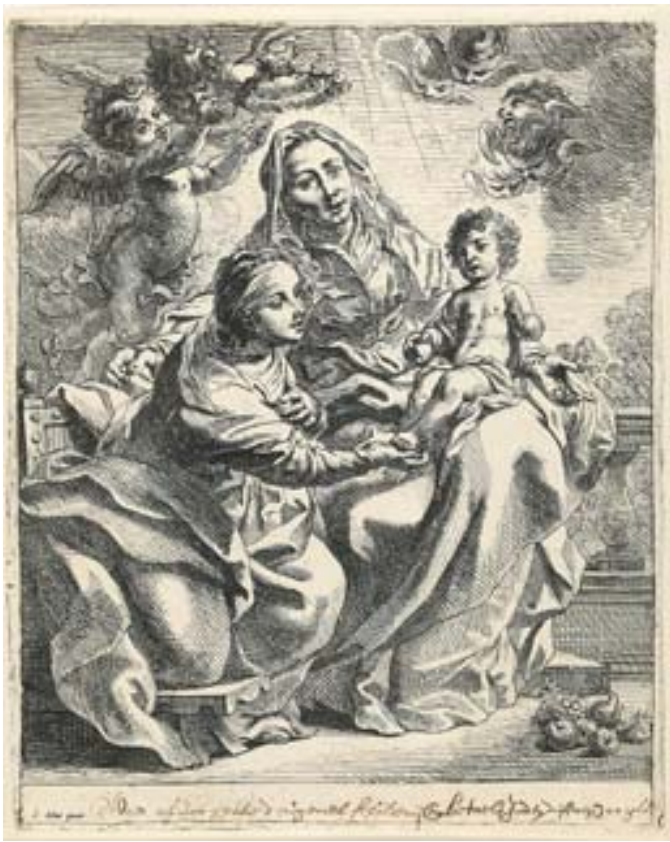

Fig. 4. Remoldus Eynhoudts según Cornelis Schut. Santa Ana con la Virgen y el Niño (Santa Ana Trinitaria). Grabado.

Próxima en estilo es una Sagrada Familia con San Juanito que conserva la iglesia de la Santa Virgen de Pipaix (fig. 5) ${ }^{46}$. Es obra de desconocida autoría donde identificamos el estilo de Cornelis Schut. La Virgen, análoga en varias versiones conocidas con la Adoración de los Magos $^{47}$, está sentada en un pórtico con el Niño Jesús sobre el regazo, dirigiendo la mirada a San Juanito que, desde el suelo, tiende las manos hacia ellos. Detrás llega San José, con un fruto en la mano. Las simbólicas uvas están aquí sobre la mesilla a la derecha. La columna y el cortinaje portado por un ángel en lo alto completan una composición de rico decorado. La cartela que rodea la cruz del Niño lleva inscritas las letras "B.V.O.", iniciales de Bid voor Ons (en flamenco, "ruega por nosotros").

Otras obras de su mano hemos identificado en el Patrimonio belga. Ya advertimos de la existencia de dos en la colegiata de Santa Gertrudis de Nivelles, con ocasión al estudio de la pintura de Peter Thijs que allí identificamos y publicamos en estas mismas páginas ${ }^{48}$.

El Martirio de San Adrian (fig. 6$)^{49}$ es lienzo de gran tamaño y asunto desconocido en la producción del pintor. Se tiene por obra de Theodoor van Thulden, y como tal está recogida en los inventarios ${ }^{50}$. La confusión puede deberse a parecidos con el lienzo del mismo asunto atribuido a Van Thulden en la iglesia de san Miguel de Gante ${ }^{51}$.

Oficial del ejército de Diocleciano convertido al cristianismo, San Adrián fue encarcelado y martirizado en el año 290. La mujer que figura a sus pies es su esposa Natalia. Según la leyenda se coló en su celda disfrazada de hombre ${ }^{52}$, detalle anecdótico que el pintor omite aquí, ataviándola con rico vestido y perlas en el cabello.

\footnotetext{
${ }^{46}$ Lienzo, 164 x 114 cm. Pipaix, Eglise Sainte-Vierge (autor desconocido). (Cliché kik-irpa : M31634).

47 Véase Vlieghe, 1967: 191. Wilmers, 1996, cats. A50, A51 y C7 (no vemos motivos para el rechazo de esta última en la monografía de Wilmers, que desconoce su paradero. No obstante, una fotografía en la documentación del Louvre la señala como firmada, fechada en 1652 (lienzo, 127 x $187 \mathrm{~cm}$ ), y conservada en la Fundación Porizynsk de Varsovia).

${ }^{48}$ SAnzsalazar, 2009: 81, nn. 23.

${ }^{49}$ Lienzo, 318 x $233 \mathrm{~cm}$. Nivelles, Collégiale Sainte-Gertrude. La fotografía se debe a Philippe Godart, del Royal Photoclub "Entre nous" de Nivelles, a quien expresamos nuestro agradecimiento.

${ }^{50}$ Estaba colocada en la Capilla de Notre-Dame de Victoires, en el brazo Norte del transepto occidental, también llamada capilla "Madame", pues era donde asistía a la misa la abadesa, que tenía acceso directo desde el palacio. Fue sufragada por la abadesa Adrienne de Lannoy (+1654). Se añade que le retable est orné d'un tableau de Théodore van Thulden, représentant le martyre de saint Adrian (TARLIER y WAUTERS, 1859: 133). En 1912 sigue en la misma ubicación, como escuela flamenca del siglo XVII. Se añade que fue atribuido a Van Thulden (Inventaire-Nivelles 1912: 7), igual que en el inventario de 1938 (Mary, 1938). Información facilitada por Martine Osterrieth, Conservadora del Museo Comunal de Nivelles, a quien expresamos nuestro agradecimiento. Hairs admite la atribución a van Thulden con reservas (HAIRs, 1977: 139, nn 83).

${ }^{51}$ Lienzo, 308 x 220 cm. Gent, Kerk Sint-Michiel (Cliché Kik-irpa: B211903), obra que creemos de Jan van den Hoecke (Sanzsalazar, 2013, pp. 1-5, fig. 1).

${ }^{52}$ RÉAU, 1958, III, I: 23.
} 
Es grande la veneración del santo en Flandes, debido a que sus reliquias se depositaron en parte en el monasterio de Grammont, donde se le invocó contra la peste en 1517. San Adrián es patrón de los soldados, los verdugos y los herreros. Schut lo pinta desnudo, en la escalinata de un templo pagano, ya despojado de su uniforme de guerrero, con un pie apoyado sobre el yunque, su más conocido atributo. El verdugo toma impulso para proceder a la amputación del pie izquierdo, mientras el derecho ya está en suelo, entre chorros de sangre. Un sacerdote interpela al santo, instigándolo a adorar la estatua de Apolo que está en el fondo, mientras un ángel mancebo llega desde lo alto acompañado de querubines para ofrecerle la palma del martirio y coronarlo.

Todo es agitación, tensión y movimiento en la composición dividida en dos registros, de tierra y cielo, y articulada mediante diagonales paralelas en fuga. La exageración de los gestos y de los contrastes espaciales y lumínicos es típica de los últimos años de la carrera de Schut, cuando recibe numerosos encargos de retablos. Busca romper con la simetría en las composiciones y exagera el pathos de manera teatral.

La figura de Natalia recuerda algunos prototipos femeninos del pintor que vemos en obras de

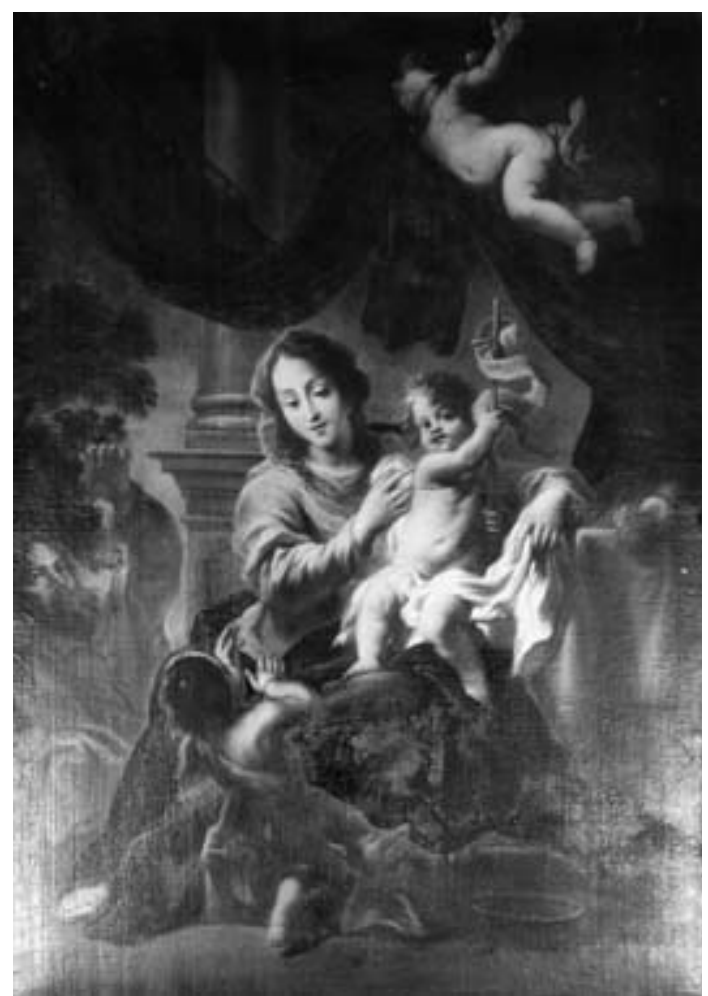

Fig. 5. Cornelis Schut. Sagrada Familia con San Juanito. Pipaix, Eglise de la Sainte-Vierge. su madurez, como la Porciúncula ${ }^{53}$, la Sagrada Familia adorada por santas y ángeles ${ }^{54}$ y la Alegoría de la Paz de Westfalia ${ }^{55}$. El modelo del sacerdote barbado a la derecha no es ajeno a San Nicolás apareciéndose a Constantino ${ }^{56}$ y los musculosos verdugos recuerdan los herreros del fresco con la Fragua de Vulcano en el casino Pescatore de Frascati, de sus años juveniles en Italia (1624-27) ${ }^{57}$. Pero el Martirio que hoy le adscribimos se asemeja particularmente, en sus aspectos compositivos, iconográficos y formales, al Martirio de San Jorge, obra de 1643 conservada hoy en el Museo de Amberes, procedente de la catedral, considerada entre las más estimables (fig. 7$)^{58}$. Repite aquí el ángel descendiendo desde lo alto con la corona y la palma del martirio, la estatua de Apolo, el sacerdote gesticulante y el jinete frente al espectador. Al tratar de este martirio conocido, Gertrude Wilmers menciona sin reproducir un grabado anónimo, basado en esta composición pero con la figura de San Adrián, con-

${ }^{53}$ Lienzo, 341 x 248 cm. Amberes, Koninklijk Museum voor Schone Kunsten. Inv. 326. WILMERs, 1996: 155, cat. A90.

${ }^{54}$ Conocida en dos ejemplares: Lienzo, 200 x $153 \mathrm{~cm}$. Hemiksem, st. Niklaaskerk. Lienzo, 235 x $200 \mathrm{~cm}$. Alemania, colección privada. Véase WILMERS, 1996: 100, cat. A38; 155, cat. A89.

${ }^{55}$ Lienzo, 266 x 365 cm. Bruselas, Musées Royaux des Beaux-Arts de Belgique. Inv. 4986. Wilmers, 1996 : 153 , cat. A88.

${ }^{56}$ Lienzo, 360 x $273 \mathrm{~cm}$. Willebroek, St Niklaaskerk (Vid. WiLmers, 1996: 72, cat. A10).

${ }^{57}$ Vlieghe, 1971. Blanchardière \& Bodart 1974. Wilmers, 1996: 62-65.

${ }^{58}$ Lienzo, 375 x $292 \mathrm{~cm}$. Amberes, Koninklijk Museum voor Schone Kunsten. Inv. 327. Descamps lo consideró como l'ouvrage le plus estimable du maître (DESCAMPS, 1769: 151. WILMERS, 1996: 130, cat. A66). 


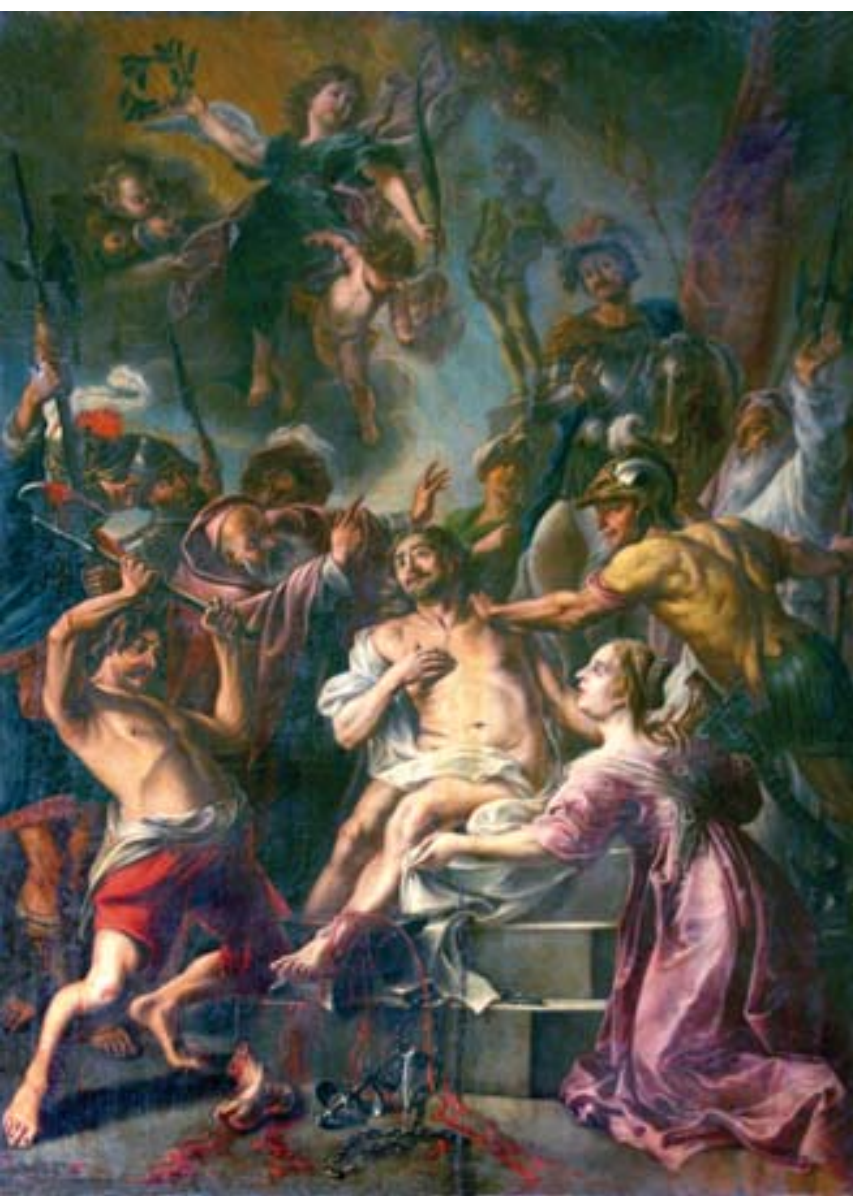

Fig. 6. Cornelis Schut. Martirio de San Adrián. Nivelles, Collégiale Sainte-Gertrude. servado en el Kupferstichkabinett de Berlín. Esperábamos que pudiera tratarse de la misma composición y solicitamos la imagen, pero el grabado deriva, en efecto, del Martirio de San Jorge y poco tiene que ver con la composición que nos ocupa ${ }^{59}$.

El segundo lienzo de la colegiata restituible a Cornelius Schut representa a San Francisco Javier dando la comunión en Extremo Oriente (fig. 8) ${ }^{60}$. Se tiene como anónimo flamenco de mediados del siglo $\mathrm{XVII}^{61}$, pero lo estimamos réplica de gran tamaño y sobre lienzo del ejemplar conocido en la iglesia de San Carlos Borromeo de Amberes, pintado sobre tabla (fig. 9) ${ }^{62}$. Se piensa que esta tabla y su pendant, con San Francisco Javier evangelizando a un emperador pagano ${ }^{63}$, se concibieron para decorar la capilla de San Francisco Javier de este templo (entonces iglesia de los Jesuitas). Nada extraña la elección de un episodio de la vida de este santo navarro, el más venerado por la orden junto a San Ignacio de Loyola. En la misma capilla una pintura de Gérard Seghers lo representa arrodillado ante la Virgen y el Niño ${ }^{64}$. Cornelis Schut toma un tema impuesto por la Contrarreforma adscrita a los ideales de España.

${ }^{59}$ Cit. WILMERS, 1996: 130. El grabado contiene la siguiente inscripción: "S. ADRANVS MARTYR NICOMEDIENSIS, CVIVS CORPS. GERARDI MONTE COLITV.” Munich, Graphische Sammlung, Inv. Nr. 33689. Nuestro agradecimiento a Susanne Wagini y a Sabine Wölfel por habernos facilitado una imagen del grabado que nos permitió descartar su hipotética correspondencia con la pintura. Informamos, no obstante, de la existencia, en la iglesia de san Nicolas de Mons, de un lienzo anónimo basado en el grabado y fechado en 1727 (Cliché kik-irpa: M224989).

${ }^{60}$ Lienzo, 300 × $200 \mathrm{~cm}$. Nivelles Collégiale Sainte Gertrude. Nuestro agradecimiento al Sr. Philippe Godart, del Royal Photoclub "Entre nous" de Nivelles, a quien se debe la fotografía.

${ }^{61}$ Tarlier y Wauters califican el cuadro de detestable (TARLIER Y WAUTERS, 1859: 133) y el decano René Mary informa sobre su procedencia en la iglesia de los Jesuitas (Mary, 1938). No sabemos de dónde recaba esta información. La iglesia de los Jesuitas, antes de San Jorge, fue atribuida a la orden en 1620, cerrada en 1773 y demolida después de 1777. Información facilitada por Martine Osterrieth, a quien reiteramos nuestro agradecimiento.

${ }^{62}$ Tabla, aprox 130 x $106 \mathrm{~cm}$. Amberes, Sint-Carolus Borromeuskerk (Véase DeZALlier, 1762: 362. Hairs, 1977 : 211. WiLMERS, 1996: 75, $\mathrm{n}^{\circ} \mathrm{A} 13$ ).

${ }_{63}$ Tabla, aprox. 130 x $160 \mathrm{~cm}$. Amberes, Sint-Carolusborromeuskerk (Véase WILMERs, 1996: 76, nº A14).

${ }^{64}$ Lienzo, aprox. $200 \times 160 \mathrm{~cm}$. Amberes, Sint-Carolus Borromeuskerk (Véase PAPEBrochius, 1700: 44. Bieneck, 1992: $\left.175, \mathrm{n}^{\circ} \mathrm{A} 54\right)$. 
San Francisco Javier fue enviado a evangelizar las Indias, pasando de Goa a Japón y a las costas de China, donde murió en 1552. Su cuerpo fue llevado a la iglesia del Buen Jesús de Goa. Se le atribuyen numerosos milagros, como la resurrección de un muerto en la India ${ }^{65}$. Menos de un siglo más tarde fue beatificado y su canonización tuvo lugar en 1622 , al tiempo que se inaugura con grandes festividades la iglesia de los Jesuitas en Amberes ${ }^{66}$.

Cornelis Schut introdujo en el fondo de la escena uno de los atributos más habituales del Santo: el crucifijo con que le obsequió San Ignacio de Loyola, que de costumbre aprisiona contra su pecho o deja entrever bajo su sotana. Omitió en cambio otros detalles habituales en su iconografía, como el cangrejo a sus pies, alusión al episodio en que el crustáceo le devolvió el crucifijo que le habían robado las olas de una tempestad en las Islas Molucas ${ }^{67}$. El pintor lo representó en rígida verticalidad, sobre un plinto en el centro de la composición, alzando el cáliz y la Sagrada Forma con

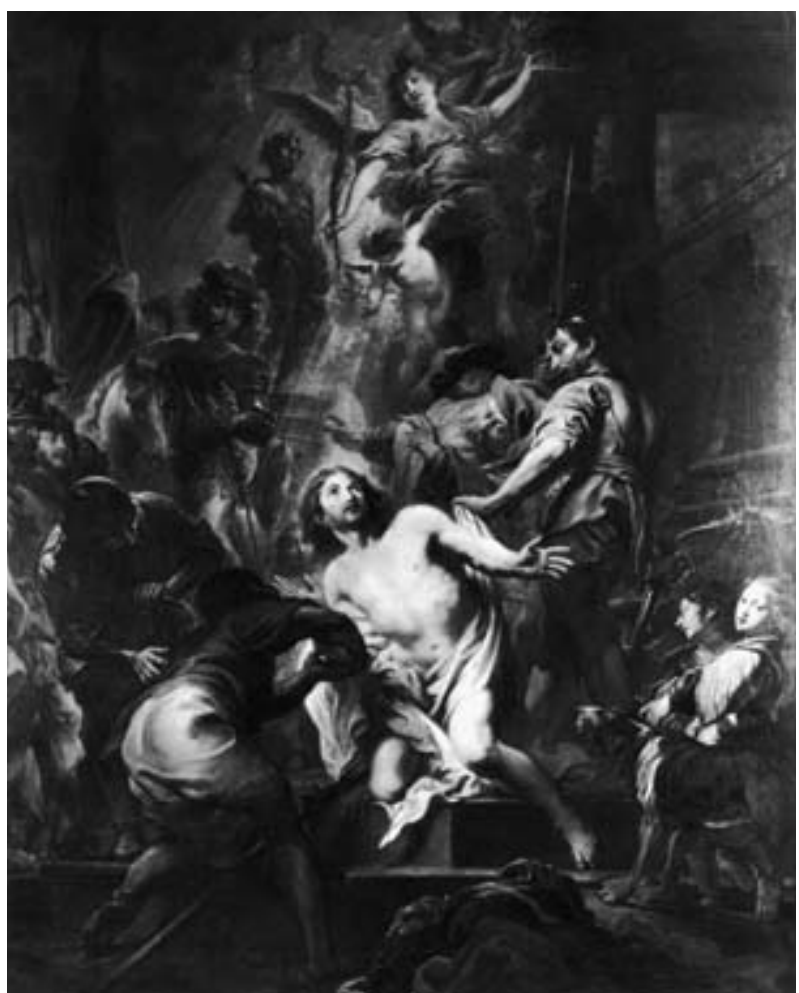

Fig. 7. Cornelius Schut. Martirio de San Jorge. Amberes, Koninklijk Museum voor Schone Kunsten. los ojos dirigidos al cielo, y pronunciando las palabras de consagración. Ocurre el milagro de la transubstanciación del pan y del vino en cuerpo y sangre de Cristo, que tanto impulsó la orden de los Jesuitas.

Es una visión de sotto in su más acentuada, con algunas diferencias en el colorido de las vestimentas y en las manos del santo, concebidas en el lienzo con mayor plasticidad. Pero lo más significativo es que el lienzo de Nivelles permite distinguir con claridad un detalle primordial que no se aprecia tan bien en la réplica de Amberes y no ha sido, por tanto, advertido. Y es que san Francisco Javier está literalmente levitando. Sus pies aparecen flotando en el espacio. De hecho, se ven por encima de un manto, proyectando una sombra en el suelo. Su levitación física, signo de su elevación espiritual, es hecho que mencionan tanto sus biógrafos como la bula de su canonización ${ }^{68}$. Quizá el pintor se vio constreñido por las menores dimensiones de la tabla, pudiendo evidenciar la levitación en un lienzo de gran tamaño como este. Las dimensiones, dicho sea de paso, son idénticas a las del Martirio de San Gereón que estuvo en la iglesia de Colonia (destruido en la II Guerra Mundial) ${ }^{69}$.

También de gran tamaño es otro lienzo en el que identificamos la mano de Cornelis Schut. Está en la iglesia de Santa Gertrudis de Malinas, decorando el altar sur, y representa a Santa Gertrudis

\footnotetext{
${ }^{65}$ RÉau, 1958, T III, vol I : 538.

${ }^{66}$ Poncelet, 1927, I: 463-470.

${ }^{67}$ RÉAU, 1958: 538.

${ }^{68}$ Monumenta XaVierana, T.II: 116-117, 332, 546, 708-709.

${ }^{69}$ Lienzo, 300 x $200 \mathrm{~cm}$. Vid Wilmers, 1996: 107, cat. A44.
} 


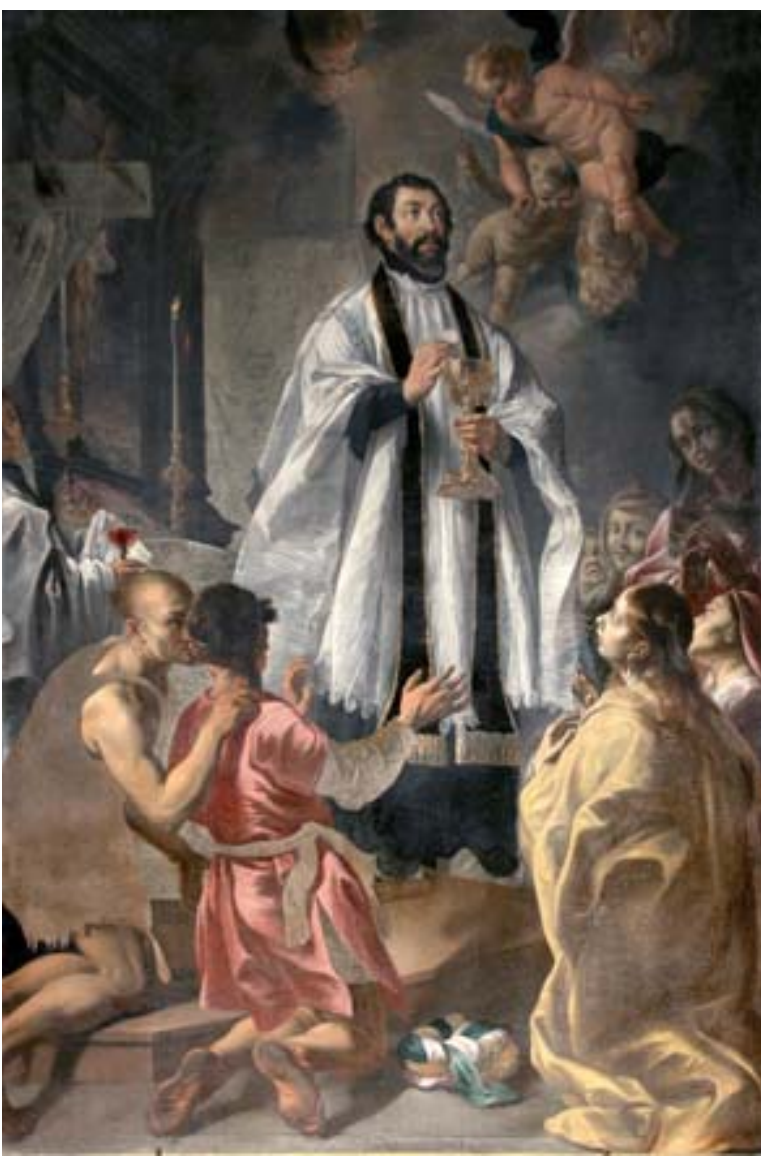

Fig. 8. Cornelis Schut. San Francisco Javier dando la comunión en Extremo Oriente. Nivelles, Collégiale Sainte Gertrude.

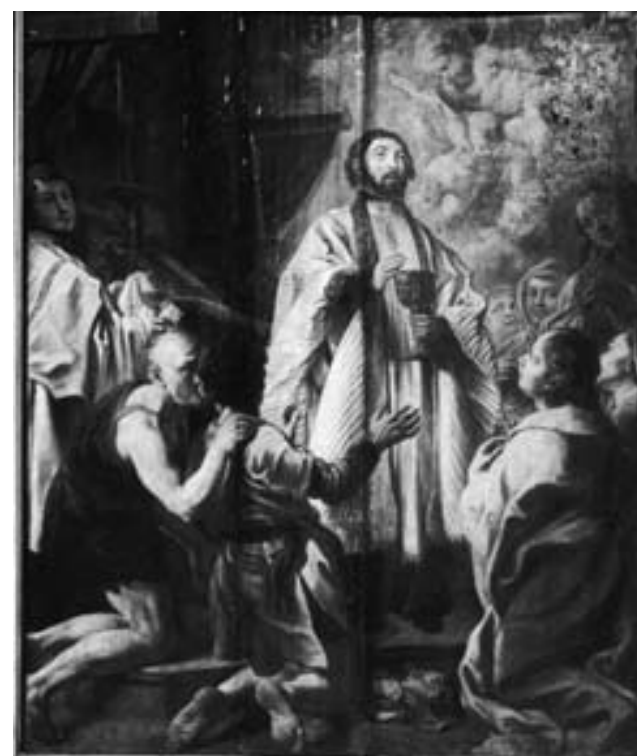

Fig. 9. Cornelis Schut. San Francisco Javier dando la comunión en Extremo Oriente. Amberes, Sint-Carolus Borromeuskerk.

en su lecho de muerte (fig. 10) ${ }^{70}$. Consta registrado en la documentación del Instituto Real de Bruselas como de Jan Cossiers y de 1634, atribución repetida en diversas publicaciones del siglo XIX ${ }^{71}$. No obstante, el estilo de Cornelis Schut se reconoce con facilidad, por ser obra característica.

Igual que en sus grandes escenas de martirios, la composición está dividida en dos registros. Santa Gertrudis, patrona de

Nivelles (626-659), figura en la parte inferior, ayudada por otra hermana a incorporarse en el lecho y recibiendo, de manos de un sacerdote, la comunión. Todas están transidas de emoción. A los pies reza, compungida, otra religiosa. En primer plano, apoyado en una mesilla, está su báculo de abadesa, su más conocido atributo. El libro de oraciones alude a su profundo conocimiento de las Sagradas Escrituras y el crucifijo, de idéntico diseño en el lienzo con San Francisco Javier, a su devoción. A la izquierda, en un altar y entre dos cirios encendidos, se ve la estatua de una santa, con la palma del martirio en la mano.

En el registro superior reconocemos las tres personas de la Santísima Trinidad, en una gloria de ángeles y santos, con Jesús coronando a un santo obispo que mira hacia lo alto con los brazos

${ }^{70}$ Lienzo, 268 x 165 cm (medidas aproximadas). Machelen, Kerk Sint-Gertrudis [Cliché kik-irpa: A53978 (atribuido a Jan Cossiers)]. La dicha iglesia posee otras pinturas de interés y desconocida autoría, como una Virgen con Niño coronada por ángeles, a nuestro parecer obra de Hendrick de Clerck [Lienzo, 145 x $116 \mathrm{~cm}$. Cliché kik-irpa: M244436 (anónimo)].

71 Romberg, 1820: 213. WaUters, 1885: 94. Cosyn, 1923: 565-570. 
abiertos, sobre cuya identidad nos interrogamos. En un principio pensamos en San Agustín, al recordar la Visión de Santa Gertrudis la Grande con San Agustín y la Santa Trinidad que se atribuye a Isidoro Redondo en el Bowes Museum. Al margen de la obsesión de San Agustín por comprender el misterio trinitario, su presencia podía explicarse por ser santo predilecto de la devoción de Santa Gertrudis (la Magna), "de quien certifica que le vio con borla de Doctor en el cielo, por su santidad, doctrina y escritos con que ilustró a la Iglesia, y alumbró al mundo" "72. Pensamos así que podía haber confusión, como a menudo sucede, con la leyenda de su homónima, Santa Gertrudis la Magna (1256-1302), muy venerada en España. Pero esta identificación no resultaba del todo convincente.

Tras no pocas pesquisas, concluimos que el santo obispo no es otro que San Patricio, con quien Santa Gertrudis de Nivelles comparte onomástica el 17 de marzo. San Patricio estaba igualmente interesado por el misterio de la Trinidad, y para explicarlo se sirvió de un trébol: de ahí que las tres personas lo coronen. La Vita Sanctae Geretrudis relata cómo el día de su muerte San Patricio la esperaba en el cielo, acompañado de ángeles elegidos por Dios y en gran gloria ${ }^{73}$. Parece ser que el monje irlandés Ultan, acompañado de su acólito Rinchinus, fue quien consoló a las hermanas

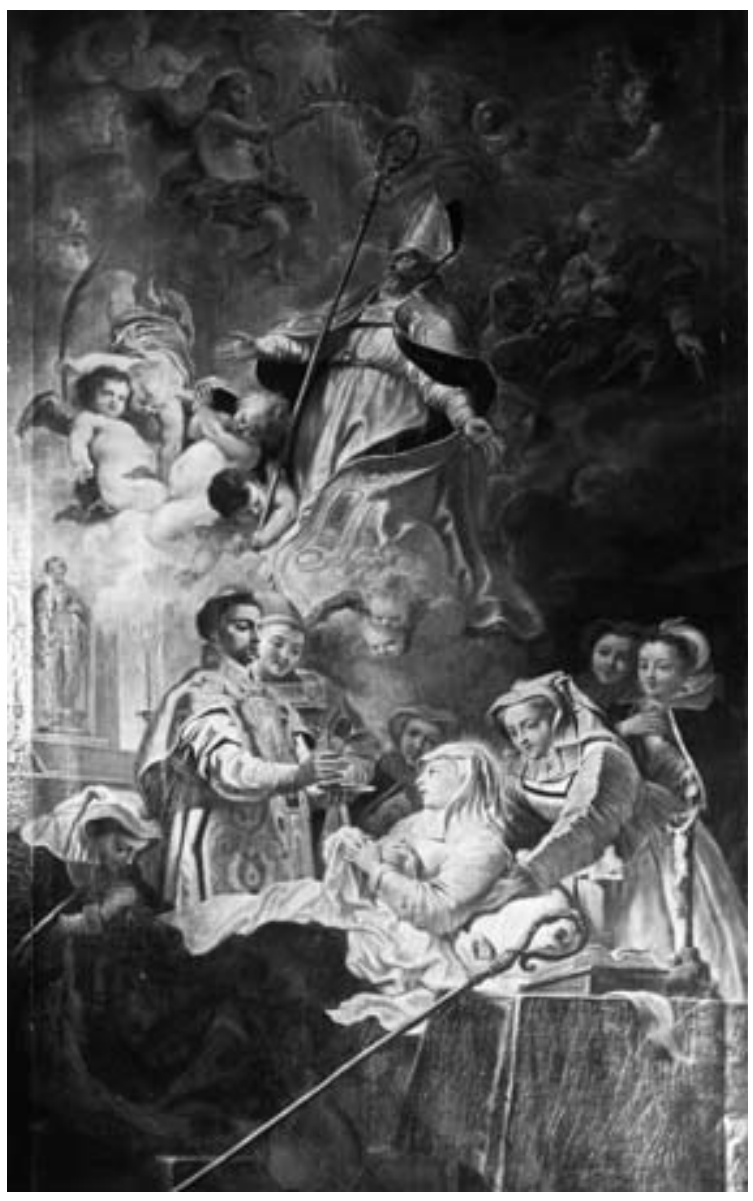

Fig. 10. Cornelis Schut. Santa Gertrudis en su lecho de muerte. Lienzo, aprox. 268 x 165 cm. Malinas, Kerk SintGertrudis. después de la muerte de Gertrudis. Entre ellas debe estar su hermana Begga, probablemente a los pies, y sus sucesoras en la orden, Wulfetrude y Agnès. Años después, un pedazo de su cama sería venerado como reliquia.

Seguramente Schut estuviera bien informado sobre la iconografía de la santa por sus contactos con los jesuitas, si bien el Acta Sanctorum correspondiente a su día, el 17 de marzo, no apareció hasta 1668, ya muerto el pintor y el editor, el jesuita Jean Bollandus. No obstante, pudo conocer narraciones más tempranas, como la publicada en Lovaina en 1632 o la de Paris, en $1612^{74}$. En cualquier caso es tema singular, poco frecuente en pintura ${ }^{75}$.

${ }^{72}$ CAstañIZA, (1782) 1804: 106.

73 Vita Sanctae Geretrudis, Vid. Fouracre y Gerberding, 1996: 326.

74 Ryckel, 1632. Descoeuvres, 1612.

${ }^{75}$ Pocas las representaciones análogas que hemos podido localizar. En la Collégiale de Sainte Gertrude de Nivelles existe una pintura anónima, con la Última comunión de Santa Gertrudis, que incluye San Patricio en lo alto (Cliché KikIrpa: M25480). 
No deja de tener relación la composición con la Aparición de San Nicolás a Constantino ${ }^{76}$, de la iglesia de San Nicolás en Willebroek, con similar disposición del protagonista y el lecho. El sacerdote es el mismo que vemos repetido en la Conversión de San Guillermo de Aquitania del Kunsthistorisches Museum de Viena ${ }^{77}$. Los modelos femeninos son los más típicos y reconocibles, como puede verse en la Alegoría de la Abundancia, en la Sagrada Familia adorada por santas ${ }^{78}$ y en las obras aquí reproducidas. Los angelitos en lo alto son análogos a los que pueblan habitualmente sus pinturas, como la Sagrada Familia con santos y la Virgen con Niño adorada por santos, ambas de la iglesia de San Carlos Borromeo, en Amberes ${ }^{79}$.

En el curso de nuestra investigación hallamos una antigua noticia olvidada, en los estudios de Constant Piron (1860), que coincide con nuestra atribución, pues menciona, entre las mejores pinturas de Schut, una Santa Gertrudis en su lecho de muerte, rodeada de hermanas ${ }^{80}$. Dado el asunto, nos preguntamos si esta obra podría tener relación con la pintura de 300 florines que el pintor promete en 1637 a un cierto padre Nicolaes, franciscano de Malinas, con la esperanza de que su hijo Peter Willem sanara de una enfermedad ${ }^{81}$. La deuda se recuerda al año siguiente, en el inventario de sus bienes tras la muerte de su primera esposa ${ }^{82}$. Su hijo fallece a final de año ${ }^{83}$ y no sabemos si la pintura llegó a realizarse.

En la iglesia de Nuestra Señora de Jezus-Eik en Overijse, a la izquierda del coro, hay un lienzo grande con la Asunción de la Virgen tenido por anónimo (fig. 11) ${ }^{84}$. Reconocemos una réplica de la pintura del mismo asunto de la iglesia de San Carlos Borromeo de Amberes (fig. $12)^{85}$. Un dibujo preparatorio, conservado en Varsovia (fig. 13) ${ }^{86}$, se asocia a esta composición conocida por desconocimiento del lienzo de Overijse. Éste corresponde con exactitud al dibujo en cuestión, como puede observarse en la disposición y número de personajes de la parte inferior y en los ángeles de lo alto. Todo esto difiere en el ejemplar de Amberes, como ya apuntó Wilmers al tratar del lienzo de Amberes en su monografía. Más próximo al dibujo, el lienzo de Overijse sería el primer intento.

Una Asunción de la Virgen de Schut poseyeron los Jesuitas de Gante. Tenida como una de sus obras más bellas, el lienzo se vendió en subasta pública en 1777 y está, desde entonces, perdido ${ }^{87}$. El catálogo de la venta apunta unas proporciones $(246,3 \times 146,2 \mathrm{~cm})$ próximas a las del lienzo que damos a conocer $(210 \times 125 \mathrm{~cm})$, lo que haría factible que se tratara del mismo; si bien, como

\footnotetext{
${ }^{76}$ Lienzo, 360 x 273 cm. Willebroek, Sint-Nicholaskerk (Vid. WiLmERS, 1996: 72, cat. A10).

${ }^{77}$ Lienzo, 193 x $124 \mathrm{~cm}$. Vid. Wilmers, 1996: 149, cat. A85.

${ }^{78}$ Véase WiLmers, 1996: cats. A34 y A38.

79 Wilmers, 1996: cats. A27, A39.

80 "Schut (Kornelis) ... Te Machelen by Vilvoorden, vindt men ook zijner beste tafeleren: de H. Gertrudis op haer sterfbed, omringd van zusters" (PIRON, 1860: 350).

81 VAn den Branden, 1883, II: 280. WiLMERs, 1996: 227.

82 Duverger, 1984-2004: IV: 145-147. WiLMERS, 1996: 228.

${ }^{83}$ GÉnARD et al., 1857: 264. Wilmers, 1996: 228.

${ }^{84}$ Lienzo, 210 x 125 cm. Overijse. Kerk O.L.Vrouw, Jezus-Eik. Cliché kik-irpa: M249796 (anónimo). Brochure van Het devote erfgoed van Jezus-Eik, 2007: 21, A (Vlaamse School, 1ste helft XVIIIe eeuw).

${ }^{85}$ Lienzo, 210 x $170 \mathrm{~cm}$. Antwerpen, St. Carolus Borromeuskerk. (Vid. WILMERS, 1996: 134-136, cat. A70).

${ }^{86}$ Lápiz y aguada marrón, 364 x $268 \mathrm{~mm}$. Varsovia, Gabinete de dibujos de la Universidad, inv. 151 (Vid. D’Hulst, 1972: 311. WILMERS, 1996: 135).

${ }^{87}$ On voit à Gand, dans l'église des Jésuites, une Assomption, beau tableau peint par Schut (DESCAMPS, 1753: 399). Les Jésuites de Gand ont de Corneille une belle Assomption (DeZallier, 1762: 362). À côté de l'Autel, on voit encore quatre pièces, dont une de Schut, représentant l'Assomption de la Ste. Vierge (MensaERT, 1763, II : 49); Dessous est une Assomption, assez joli Tableau, bien colorié, par C. Schut (Descamps, 1769: 246). Schut. L'Assomption. La Ste. Vierge est environnée d'Anges bien groupés; au bas les Apôtres en admiration. Ce Tableau semble être le Chef-d'oeuvre de ce Peintre; on voit qu'il a pris plaisir à le toucher spirituellement. Sur toile, $H$. 7 pieds 7 pouces, L. 4 pieds 6 pouces [Catalogue Jésuites, Ghent (Lannoy), 5-5-1777, nº 7]. WiLmers, 1996: 190, cat. B150.
} 


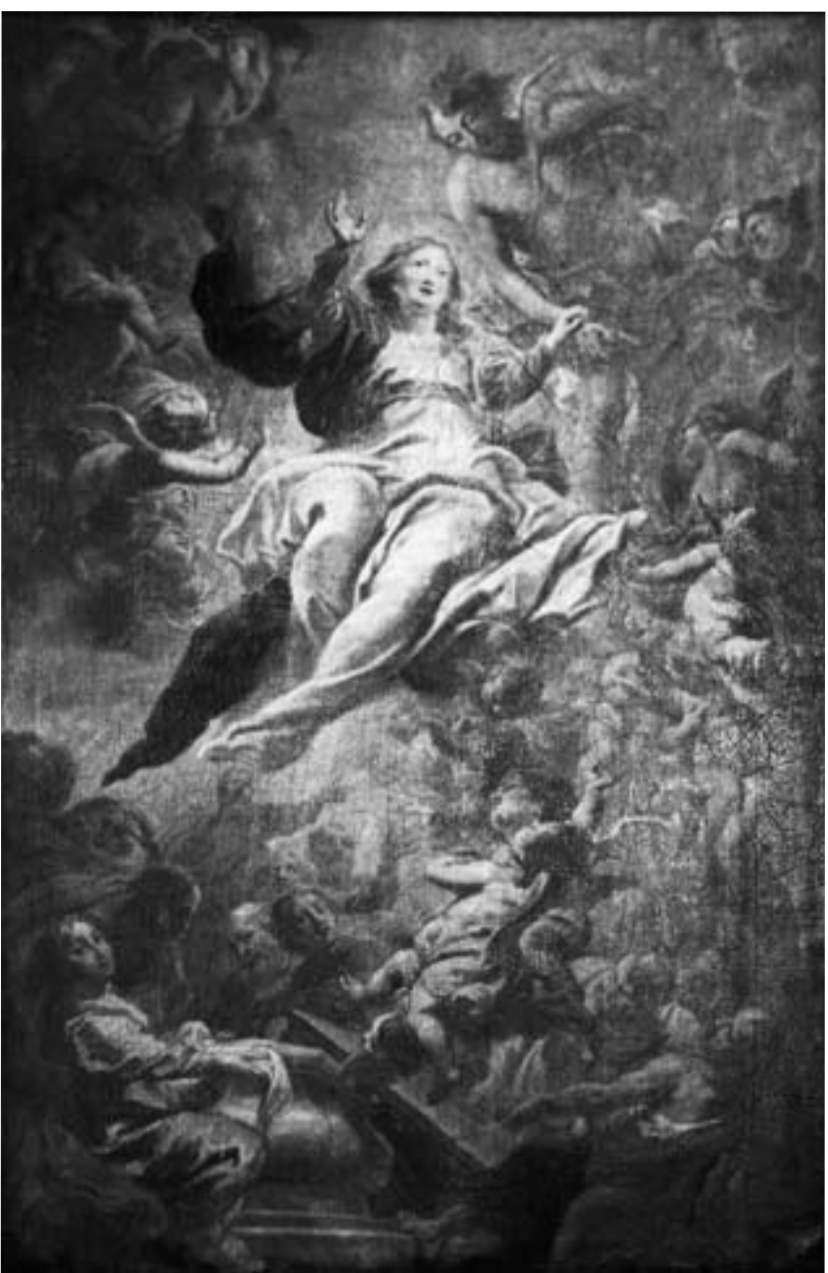

Fig. 11. Cornelis Schut. Asunción de la Virgen. Overijse. Kerk Onze Lieve Vrouw, Jezus-Eik.

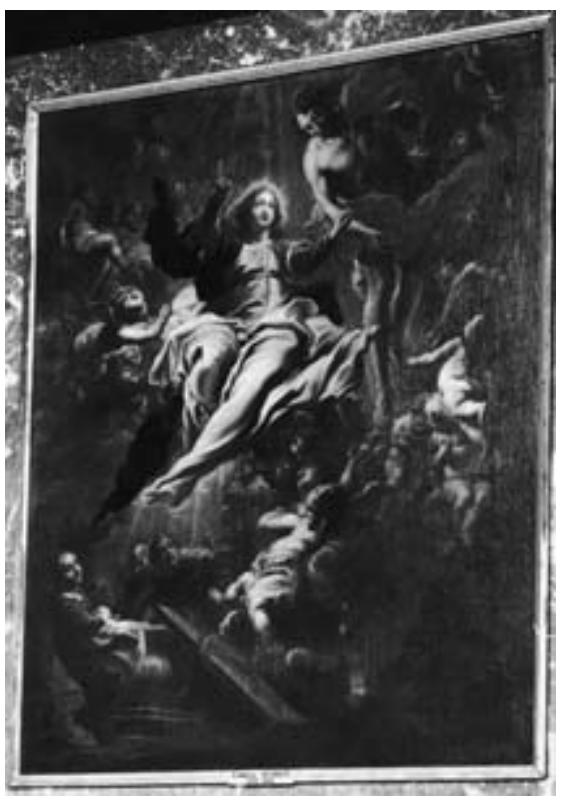

Fig. 12. Cornelis Schut. Asunción de la Virgen. Amberes, St. Carolus Borromeuskerk.

apuntó Gertrude Wilmers, dada la descripción, podría tratarse de otra composición distinta, conocida sólo por el grabado de Rombout Eynhoudts (fig. $14)^{88}$, con la Virgen en vertical, rodeada de ángeles y sin la figura de Cristo.

Pues bien, hemos hallado la composición correspondiente a dicho grabado en la iglesia de Sint-Amandus de la pequeña localidad de Aspelare, vecina a Ninove (fig. 15) ${ }^{89}$, tenida por

anónima. Es pintura de igual altura a la documentada en la venta, pero mayor en anchura $(240 \times 170$ $\mathrm{cm}$ ), ubicada en el altar norte de la iglesia. Conocemos la obra sólo por fotografía, no obstante suficiente para constatar su calidad y superioridad respecto a una réplica de taller que figuró en el comercio hace pocos años ${ }^{90}$.

Por último, entre las pinturas profanas e inéditas, quisiéramos llamar la atención sobre un lienzo de gran tamaño con la Alegoría de la Aritmética cuya fotografía encontramos en la documentación del Louvre, junto a anotaciones de Jacques Foucart, que apunta la autoría de Schut y su exportación

${ }^{88}$ Con la inscripción: "C. Schut inuent / Assumpta Est maria in Coelum / R. Eÿnhouts fecit / Ioan Meÿsens excu." (Hollstein 16, 2).

${ }^{89}$ Lienzo, 240 x $170 \mathrm{~cm}$. Aspelare, Kerk Sint-Amandus (autor desconocido). (Cliché kik-irpa: M23190).

${ }^{90}$ Lienzo, 144 x $126 \mathrm{~cm}$. Amberes, Bernaerts Veilinghuis, 21-11-2005, nº 65A (Attribué à Cornelis Schut). 


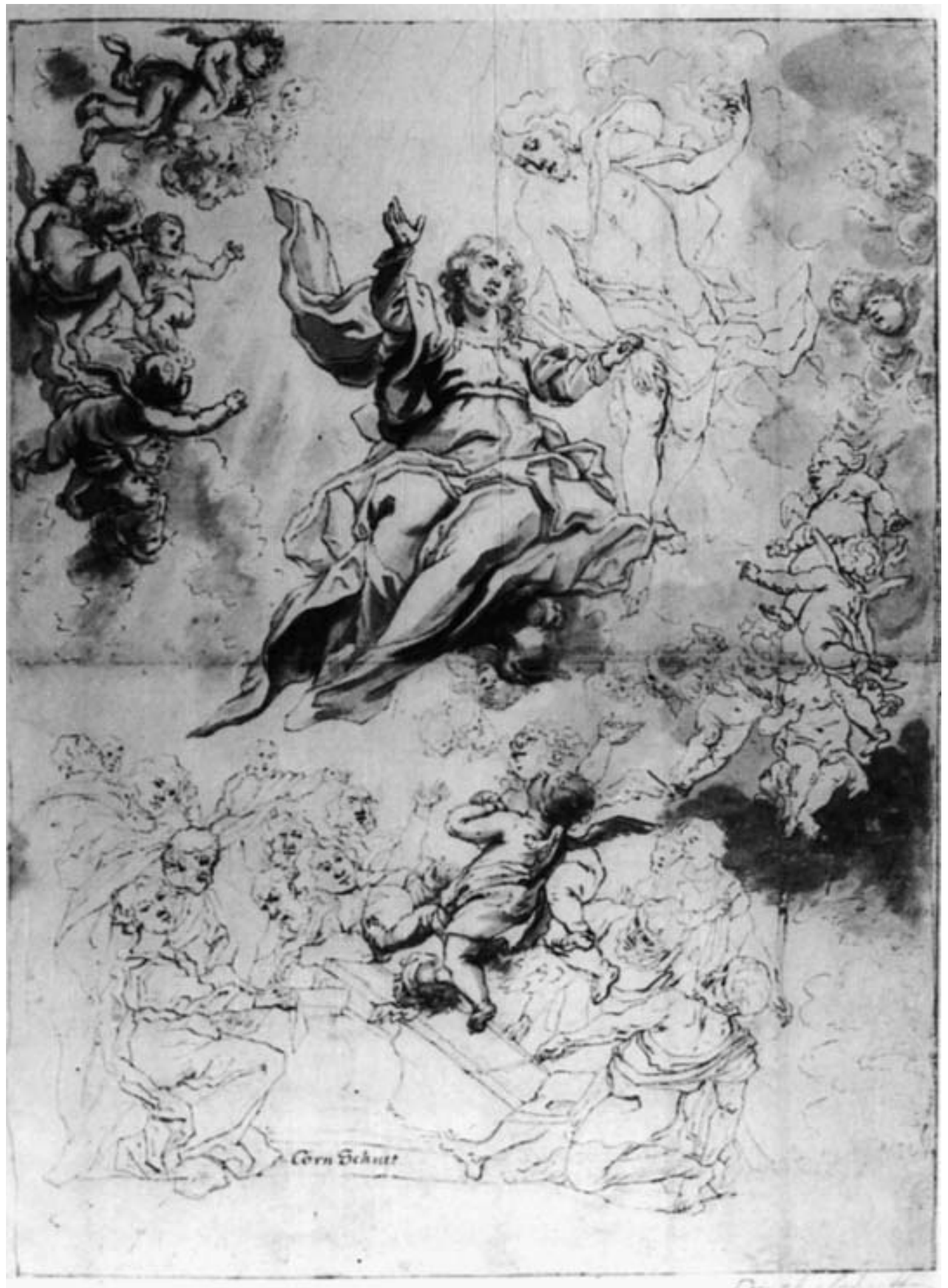

Fig. 13. Cornelis Schut I. Asunción de la Virgen. Varsovia, Gabinete de dibujos de la Universidad. 


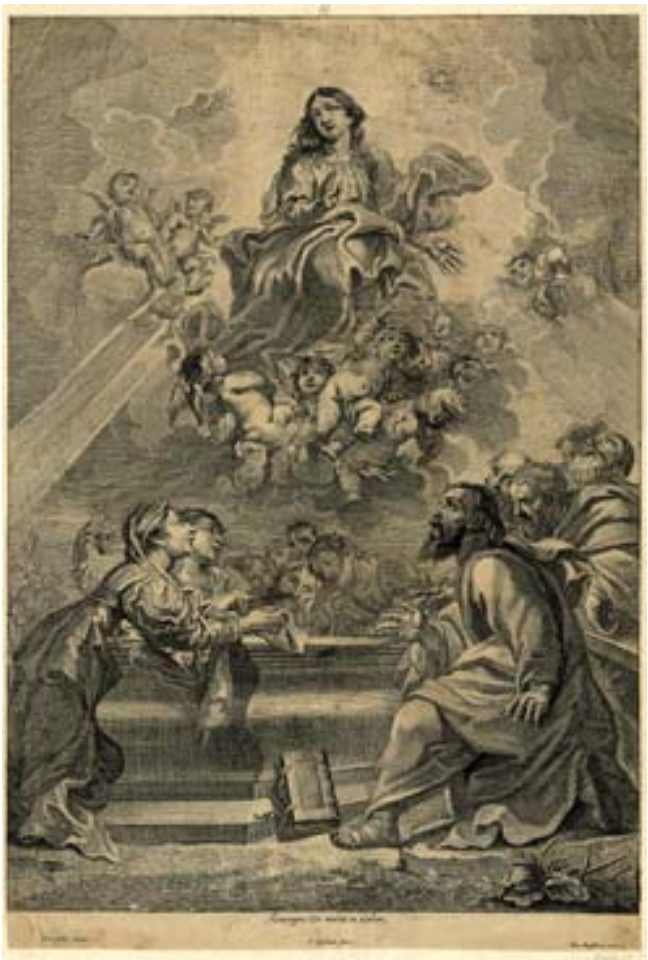

Fig. 14. Rombout Eynhoudts según Cornelis Schut. Asunción de la Virgen. Grabado.

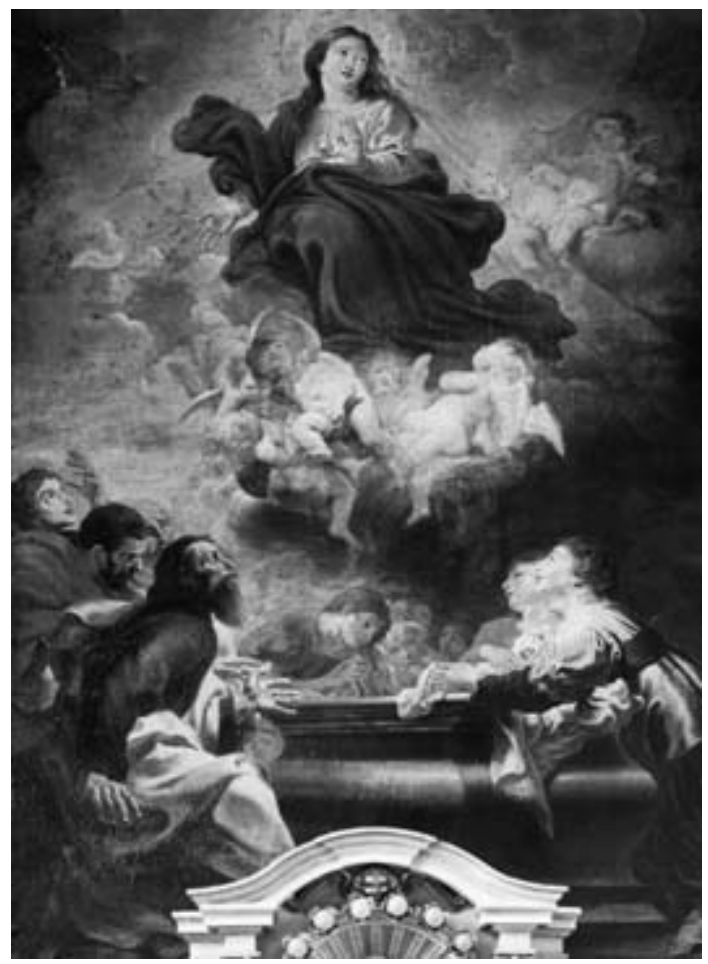

Fig. 15. Cornelis Schut. Asunción de la Virgen. Lienzo, 240 x $170 \mathrm{~cm}$. Aspelare, Kerk Sint-Amandus.

de Francia a Irlanda en $1989^{91}$. Se trata con toda probabilidad de uno de los cartones para la serie de tapices con las Artes Liberales, de la que existen, como apuntamos ya, ejemplares en España. La comparación con el boceto ${ }^{92}$ permite ver su exacta correspondencia. Igual que en las demás composiciones de la serie, tanto el cartón como el tapiz desarrollan la escena en vertical, a diferencia de los grabados, que la despliegan en horizontal. La calidad y el estilo son coherentes con los otros tres cartones conocidos ${ }^{93}$.

\footnotetext{
${ }^{91}$ Lienzo, 260 x $170 \mathrm{~cm}$. Paris, antiquaire G. Moronni. Douane du 4/X/1989 (Irlanda).

92 Tabla, 28,5 x 16,5 cm. Véase De Poorter, 1985: 251-252. Wilmers, 1996, cat. A60.

${ }^{93}$ Hoy reunidos en la Rubenhuis de Amberes (Véase De Pooter, 1985).
} 


\section{BIBLIOGRAFÍA}

Abascal y Cebrián, 2009, Juan Manuel Abascal Palazón y Rosario Cebrián, Los viajes de José Cornide por España y Portugal de 1754 a 1801, Madrid, Real Academia de la Historia, 2009.

Alamán 1855, Lucas Alamán, "Schut", in Diccionario universal de historia y de geografia, T. VII, México, 1855: 17.

Angulo Íñiguez 1971, Diego Angulo Iñiguez, Pintura española del siglo XVII. Ars Hispaniae XV, Madrid, 1971.

Areán, 1989, Carlos Areán, “Los fondos de Arte en Cajamadrid”, Galería, Arte, Coleccionismo, Inversión $\mathrm{n}^{\circ}$ 1, Madrid (enero 1989): 24-29.

Asselberghs, 1999, Jean Paul Asselberghs, Los Tapices flamencos de la Catedral de Zamora, Salamanca, 1999.

Begheyn 2007, Paul Begheyn SJ, "Franciscus Xavierus doopt de Indiërs. Een onbekende schilderij van Cornelis Schut bij de jezuïten in Brugge”, Vlaanderen Kunsttijdschrift 56 (April, 2007): 98-99.

Bieneck, 1992, Dorothea Bieneck, Gerard Seghers 1591-1651. Leben und Werk des Antwerpener Historienmalers, Lingen, 1992.

Blanchardière \& Bodart 1974, Noelle de la Blanchardière y Didier Bodart, « Pietro Pescatore e gli affreschi di Cornelis Schut e di Timan Craft al Casino Pescatori di Frascati », Arte illustrata 58 (julio 1974): 179189.

Caljé van den Berg, 1973, Ellen Caljé van den Berg, "Vincent van der Vinnes Ein-driicke in Koln. 16521653”, Wallraf Richartz Jahrbuch XXXV (1973): 281-308.

Capmany y Montpalau, 1862, Antonio Capmany y Montpalau, Museo histórico, que comprende los principales sucesos de España y el Extranjero, vol. II, $2^{\mathrm{a}}$ ed. Madrid, 1862.

Castañiza (1782) 1804, Juan de Castañiza, Vida de la prodigiosa virgen Santa Gertrudis la Magna, abadesa de Eislebio en el condado de Mansfeldense de la orden del glorioso padre y patriarca de los monges San Benito, Madrid, 1804, 1 ed. 1782.

Catalogue Jésuites, 1777, Catalogue des tableaux qui ont appartenu aux Collèges des ci-devant Jésuites de Gand, Ipres, Courtray, Tournay \& Bruges. Ces tableaux sont déposés à Gand, 5 Mai, 1777.

Clavijo García, 1981, Agustín Clavijo García, "La Iglesia-Hospital de San Julián de Málaga: historia y Arte", Boletín del Museo Diocesano de Arte Sacro 1-2, (Málaga 1981): 47-84.

Cosyn 1923, Arthur Cosyn, "L'église et le château de Machelen", Bulletin du Touring Club de Belgique (TCB), 1923: 565-570.

D’Hulst, 1972, Roger A. d'Hulst, "Enkele tekeningen van Cornelis Schut”, Nederlands kunsthistorisch Jaarboek XXII (1972): 303-316.

De Bie, 1661, Cornelis de Bie, Het Gulden Cabinet van de Edele Vry Schilderconst, Antwerpen, 1661.

De la Sierra \& Lorenzo y Quiles, 1998, Alonso de la Sierra, Fernando Lorenzo y Quiles, «Nuevas obras de Cornelio Schut el Joven», Norba-Arte, XVIII-XIX (1998-199): 83-105.

De Poorter, 1985, Nora de Poorter, "Cornelis Schut als tapijtontwerper: de reeks van de Zeven Vrije Kunsten", in Rubens and His World. Bijdragen aan Prof.Dr. Ir. R-A. d'Hulst, (Antwerpen, 1985): 245-263.

Delmarcel y Duverger, 1987, Guy Delmarcel y Erik Duverger, Brugge en de tapijtkunst / Bruges et la tapisserie, cat.exp. (Bruges, Gruuthusemuseum \& Memlingmuseum), Mouscron/Bruges 1987.

Denucé 1932, Jan Denucé, De Antwerpsche 'Konstkamers' in de 16 de en 17 de eeuwen. Inventarissen van Kunst verzamelingen, (Bronnen voor de Geshiedenis van de Vlaamsche Kunst II), Antwerpen, 1932.

Descamps, 1753 , Jean Baptiste Descamps, La vie des peintres flamands, allemands et hollandois..., Paris, 1753.

Descamps, 1769, Jean Baptiste Descamps, Voyage pittoresque de la Flandre et du Brabant, Paris, 1769.

Descoeuvres, 1612, Guillaume Descoeuvres, Vie de sainte Gertrude, fondatrice du monastère de Nivelles, in 12, Paris, 1612.

Dezallier, 1762, Antoine Joseph Dezallier d' Argenville, Abrégé de la vie des plus fameux peintres, avec leur portraits gravés en taille-douce ..., t. III, Paris, 1762.

Díaz Padrón, (en preparación), Matías Díaz Padrón, “Tres nuevas pinturas de Cornelis Schut en España” (en preparación). 
Díaz Padrón, 1976, Matías Díaz Padrón, La pintura flamenca del siglo XVII en España, ms. Tesis doctoral, Universidad Complutense de Madrid, 1976, XII vols.

Díaz Padrón, 1987, Matías Díaz Padrón, "Tres pinturas de Cornelio Schut el Joven en colecciones madrileñas", Archivo Hispalense. Revista histórica, literaria y artística, 70, nº 214, 1987: 205-210.

Díaz Padrón, 2004, Matías Díaz Padrón, "El tercer Rapto de Europa de Cornelis Schut", Goya. Revista de Arte, 299, 2004: 80-84.

Duverger, 1984-2004, Erik Duverger, Antwerpse Kunstinventarissen uit de zeventiende eeuw. Fontes Historiae Artis Neerlandicae Bronnen voor de Kunstgeschiedenis van de Nederlanden, Bruselas, XIII vols., Antwerpen, 1984-2004.

Duverger, 1989, Erik Duverger, "Inventaris van het sterfhuis van Elizabeth Waeyens (+1657), weduwe van Hans van Mildert", Koninklijk Museum voor Schone Kunsten Antwerpen Jaarboek, (Antwerpen, 1989): 387-414.

Ferguson 1966, Georges Ferguson, Signs \& Symbols in Christian Art, New York, 1966.

Fouracre y Gerberding, 1996, Paul Fouracre y Richard A. Gerberding, "Vita Sanctae Geretrudis (The Life of St Geretrud) and the Additamentum Nivialense de Fuilano (the Nivelles supplement to the Vita Fursei concerning Foillan", in Late Merovingian France. History and hagiography 640-720, Manchester 1996: 301-330.

Gálvez, 1926, S. J. C. Gálvez, "Los cuadros de San Francisco Javier en el Colegio Imperial”, La estrella del mar 7 (1926): 670-674, 736-738.

Génard et al., 1857 , Pierre Génard et al., Catalogue du Musée d'Anvers, Anvers, 1857.

Gómez y Chillón, 1925, Amando Gómez y Bartolomé Chillón, Los Tapices de la Catedral de Zamora, Cabildo de la Catedral, Zamora, 1925.

Génard, 1882, Pierre Génard, «L'Aiguière de Rubens dite des Archiducs Albert et Isabelle », Bulletin Rubens I (1882) : 224-244.

Gutiérrez Pastor, 2007, Ismael Gutiérrez Pastor, "Sobre las pinturas del Colegio Imperial de Madrid en Santa Cruz de Retamar (Toledo): una inédita Nuestra Señora del Amparo del estilo de Francisco de Zurbarán", Anuario del Departamento de Historia y Teoría del Arte, Universidad Autónoma de Madrid, vol. XIX (Madrid 2007): 105-119.

Hairs 1977, Marie-Louise Hairs, Dans le sillage de Rubens. Les peintres d'histoire anversois au XVII siècle, Liège, 1977.

Hollstein, F. W. H. Hollstein, Dutch and Flemish Etchings, Engravings and Woodcuts ca. 1450-1700, Amsterdam 1949-1987; Roosendaal 1988-1994; Rotterdam 1995.

Inventaire-Nivelles 1912, Inventaire des objets d'art existant dans les édifices publics des communes de l'arrondissement de Nivelles, Comité des correspondants de la Commission Royale des Monuments et Sites de la Province du Brabant, Bruxelles, 1912.

Kinkead, 1982, Duncan T. Kinkead, "Pintores flamencos en la Sevilla de Murillo", Archivo Hispalense. Revista histórica, literaria y artística LXIV, 195 (1982): 37-54.

Lille/Calais/Arras, 1977, Hervé Oursel, Jacques Foucart, Jean Lacambe, Françoise Maison et al., La peinture flamande au temps de Rubens. Trésors des musées du Nord de la France, cat. exp. Lille/Calais/Arras, 1977.

Maier, 2005, Jorge Maier et al., Real Academia de la Historia. Catálogo del Gabinete de Antigüedades. Antigüedades siglos XVI-XX, Madrid, 2005.

Mary, 1938, René Mary, Inventaire du mobilier de la Collégiale Ste Gertrude, Nivelles, 1938.

Monumenta Xaveriana (1899-1912), Monumenta Xaveriana ex autographis vel ex antiquioribus exemplis collecta (Monumenta Historica Societatis Iesu, 16, 43), 2 vols. Matriti, 1899 y 1912.

Papebrochius 1700, P. Daniel Papebrochius, Annales Anverpienses, ab urbe condita ad annum MDCC. collecti ex ipsius civitatis monumentis, publicis privatisque Latinae ac patriae linguae iisque fere manu exaratis, (1700), ed. M. \& E. Buschmann, IV, 1847: V, 1848.

Paris, 1977, Jacques Foucart y Jean Lacambre, Le siècle de Rubens dans les collections publiques françaises, cat.exp. Paris (Grand Palais), 1977.

Piron, 1860, Constant F. A. Piron, Algemeene levensbeschryving der mannen en Vrouwen van België, welke zich door hunne dapperheid, vernuft, geest, wetenschappen, kunst, deugden, dwalingen of misdaeden eenen naem verworven hebben, sedert de eerste tyden tot den dag van heden, Machelen, 1860.

Arch. esp. arte, LXXXVI, 343, JULIO-SEPTIEMBRE 2013, 201-220, ISSN: 0004-0428 
Poncelet, 1927, Alfred Poncelet, Histoire de la Compagnie de Jésus dans les anciens Pays-Bas. Etablissement de la Compagnie de Jésus en Belgique et ses développements jusqu'à la fin du règne d'Albert et d'Isabelle, Mémoires de l'Académie royale de Belgique, Bruxelles, 1927-28, 2 vols.

Ponz, 1772-1794, Antonio Ponz, Viage de Espana, o cartas, en que se da noticia de las cosas mas apreciables, $y$ dignas de saberse que hay en ella, Madrid, J. Ybarra, 1772-1794, 18 vols.

Réau, 1958 , Louis Réau, Iconographie de l'Art Chrétien, Paris, 1958.

Romberg, 1820, J.B. Romberg, New Picture of Brussels and its environs or, Stranger's guide to the curiosities of that interesting city, $2^{\mathrm{a}}$ ed., London, 1820.

Ryckel 1632, J. Geld. A. Ryckel, Aliae vitae et miracula. Vitae S. Gertrudis abatissae Nivellensis, Lovanii, 1632.

Sánchez Cantón, 1952, Javier Sánchez Cantón, Cuarto Centenario de la muerte de San Francisco Javier, Discursos leidos en la Junta Solemne Conmemorativa de 26 de enero de 1952, Madrid, 1952.

Sanzsalazar, 2009, Jahel Sanzsalazar, "Una nueva pintura de Peter Thijs identificada en la colegiata de Santa Gertrudis de Nivelles (Valonia), Archivo Español de Arte 325, enero-marzo, (Madrid, 2009): 79-86.

Sanzsalazar, 2013, Jahel Sanzsalazar, "Jan van den Hoecke: quelques précisions et nouvelles propositions pour le catalogue de son oeuvre", Revue Belge d'Archéologie et d'Histoire de l'Art, Académie Royale d'Archéologie de Belgique, 2013, pp. 1-36.

Sanzsalazar (en preparación), Jahel Sanzsalazar, "Nuevas guirnaldas de Cornelis Schut".

Sauret Guerrero, 1999, Teresa Sauret Guerrero, Patrimonio cultural de Málaga y su provincia: Edad moderna: arquitectura y urbanismo, Málaga, 1999.

Tarlier y Wauters, 1859, Jules Tarlier y Alphonse Wauters, La Belgique ancienne et moderne. Géographie et histoire des communes belges (Arrondissements de Nivelles et de Louvain), Bruxelles, 1859.

Van de Velde \& Vlieghe, 1967, Carl van de Velde, Hans Vlieghe, Stadsversieringen te Gent in 1635 voor Bleijde Intrede van de Kardinaal-Infant, Gent, 1967.

Van den Branden, 1883, F. Joost van den Branden, Geschiedenis der Antwerpsche Schildersschool, vol. II, Antwerpen, 1883.

Vlieghe, 1967, Hans Vliegue, "Niuewe toeschrijvingen aan Cornelis Schut", Jaarboek van het Koninklijk Museum voor Schone Kunsten Antwerpen, 1967: 187-198.

Vlieghe, 1969-1972, Hans Vlieghe, "Enkele getenkende Modelli door Cornelis Schut", Gentse bijdragen tot de kunstgeschiedenis en de oudheidkunde XXII (1967-1972): 183-197.

Vlieghe, 1971, Hans Vlieghe, "Zu den römischen Jahren des Malers Cornelis Schut”, Mitteilungen des Kunsthistorischen Institutes in Florenz XV, (1971): 207-218.

Vlieghe, 1972, Hans Vlieghe, Saints (Corpus Rubenianum Ludwig Burchard), Phaidon, London-New York (1972), 2 vols.

Vlieghe, 1972a, Hans Vlieghe, Gaspar de Crayer. Sa vie et ses æeuvres, Bruxelles, 1972.

Vlieghe, 1990, Hans Vlieghe, "Cornelis Schut in Italy", Hoogsteder-Nauman Mercury 11, (1990): 28-41.

Wauters, 1855, Alfonse Wauters, Histoire des environs de Bruxelles ou description historique des localités qui formaient autrefois l'Ammannie de cette ville, vol. II, Bruxelles, 1855.

Wilmers, 1996, Gertrude Wilmers, Cornelis Schut (1597-1655). A Flemish Painter of the High Baroque, Brepols: 1996.

Wurzbach, Alfred von Wurzbach, Niederländisches Künstler-Lexikon auf Grund archivalister Forschungen, Viena-Leipzig, 1906-1911, 3 vols.

Fecha de recepción: 12-I-2012

Fecha de aceptación: 27-VIII-2012 